\title{
Age-Related Changes in Frontal Network Structural and Functional Connectivity in Relation to Bimanual Movement Control
}

\author{
마akuei Fujiyama, ${ }^{1}$ Jago Van Soom, ${ }^{1}$ Guy Rens, ${ }^{1}$ Jolien Gooijers, ${ }^{1}$ Inge Leunissen, ${ }^{1}$ Oron Levin, ${ }^{1}$ \\ and Stephan P. Swinnen ${ }^{1,2}$ \\ ${ }^{1}$ Motor Control Laboratory, Movement Control and Neuroplasticity Research Group, Group Biomedical Sciences, 3001, Leuven, Belgium, and 2Leuven \\ Research Institute for Neuroscience and Disease, 3001, Leuven, Belgium
}

Changes in both brain structure and neurophysiological function regulating homotopic as well as heterotopic interhemispheric interactions (IHIs) are assumed to be responsible for the bimanual performance deficits in older adults. However, how the structural and functional networks regulating bimanual performance decline in older adults, as well as the interplay between brain structure and function remain largely unclear. Using a dual-site transcranial magnetic stimulation paradigm, we examined the age-related changes in the interhemispheric effects from the dorsolateral prefrontal cortex and dorsal premotor cortex onto the contralateral primary motor cortex (M1) during the preparation of a complex bimanual coordination task in human. Structural properties of these interactions were assessed with diffusion-based fiber tractography. Compared with young adults, older adults showed performance declines in the more difficult bimanual conditions, less optimal brain white matter (WM) microstructure, and a decreased ability to regulate the interaction between dorsolateral prefrontal cortex and M1. Importantly, we found that WM microstructure, neurophysiological function, and bimanual performance were interrelated in older adults, whereas only the task-related changes in IHI predicted bimanual performance in young adults. These results reflect unique interactions between structure and function in the aging brain, such that declines in WM microstructural organization likely lead to dysfunctional regulation of IHI, ultimately accounting for bimanual performance deficits.

Key words: aging; bimanual coordination; interhemispheric communication; MRI; transcranial magnetic stimulation

Significance Statement

The structural and functional changes in the aging brain are associated with a decline in movement control, compromising functional independence. We used MRI and noninvasive brain stimulation techniques to investigate white matter microstructural organization and neurophysiological function in the aging brain, in relation to bimanual movement control. We found that less optimal brain microstructural organization and task-related modulations in neurophysiological function resulted in poor bimanual performance in older adults. By interrelating brain structure, neurophysiological function, and behavior, the current study provides a comprehensive picture of biological alterations in the aging brain that underlie declines in bimanual performance.

\section{Introduction}

Bimanual movements are a hallmark of human motor skills requiring both hands to work in a coordinated manner to accom-

Received Aug. 20, 2015; revised Nov. 5, 2015; accepted Dec. 9, 2015.

Author contributions: H.F., 0.L., and S.P.S. designed research; H.F., J.V.S., and G.R. performed research; H.F., J.V.S., J.G., I.L., 0.L., and S.P.S. analyzed data; H.F., J.G., I.L., 0.L., and S.P.S. wrote the paper.

This work was supported by KU Leuven Research Fund Grant C16/15/070, Flanders Fund for Scientific Research Grants G0721.12 and G0708.14, and the Interuniversity Attraction Poles Program initiated by the Belgian Science Policy Office P7/11. H.F., J.G., and I.L. were supported by the Flanders Fund for Scientific Research (postdoctoral fellowships). We thank Dr. Samuel A. Hurley (Oxford University) for DWI image processing and Jean-Christophe Houde (University of Sherbrooke) for his technical support on the visualization of the fiber tracts.

The authors declare no competing financial interests.

Correspondence should be addressed to Dr. Hakuei Fujiyama, Movement Control and Neuroplasticity Research Group, KU Leuven, 3001, Leuven, Belgium. E-mail: Hak.Fujiyama@faber.kuleuven.be. plish a common goal (Swinnen and Gooijers, 2015). With advancing age, bimanual performance shows declines, profoundly impacting activities of daily living and quality of life. In particular, performing complex bimanual movements requires more effortful processing in older adults (Swinnen et al., 1998; e.g., Summers et al., 2010). It has been suggested that age-related functional changes in interhemispheric interaction (IHI) between primary motor cortices (M1s) via fibers of the corpus callosum (CC) (Gazzaniga, 2005) are, at least partly, responsible for motor performance declines (Talelli et al., 2008; Fling and 
Seidler, 2012). This view is further supported by recent structural imaging work demonstrating associations between age-related declines in bimanual motor performance and changes in the microstructural organization of the CC subregions connecting homologous brain areas, including both M1s (Serbruyns et al., 2015).

Typically, fMRI and transcranial magnetic stimulation (TMS) studies have shown that older adults recruit wider brain regions to perform cognitive and motor tasks (Mattay et al., 2002; Heuninckx et al., 2005; Fujiyama et al., 2010; Goble et al., 2010; Fujiyama et al., 2012), and interactions between brain regions become more pronounced in the aging brain (Ward, 2006; Reuter-Lorenz and Cappell, 2008; Heitger et al., 2013). More specifically, older adults show greater reliance on interhemispheric interactions between dorsal premotor cortex (PMd) and contralateral M1 during a sensorimotor reaction time task relative to young adults (Hinder et al., 2012). In the context of bimanual movement, disinhibitory IHIs between M1s assessed at rest were found to predict better performance in older adults (Fling and Seidler, 2012). However, to date, no studies have addressed interhemispheric projections from nonprimary motor areas to the contralateral M1 for the performance of bimanual movements in older adults. The basic motor network dynamically extends into parietal, temporal, and prefrontal regions as task complexity increases (Swinnen and Wenderoth, 2004). In addition, given that M1s are relatively resistant to age-related changes (Barrick et al., 2010), the relative importance of interhemispheric influences exerted from nonprimary motor regions during more complex movement conditions is likely to increase with advancing age (Hinder, 2012).

Notably, the reported changes in brain structure and neurophysiological function contributing to the bimanual performance decline in older adults were derived from studies that assessed these two underlying mechanisms independently. As such, direct evidence linking these phenomena via a straightforward relationship between brain structure, neurophysiological function, and behavior, while considering wider brain networks necessary for the performance of a complex bimanual movement, does not exist. It is therefore crucial to empirically investigate how brain structure and neurophysiological function interact to regulate behavior. Thus, task-related IHI modulations during complex bimanual movements were assessed as well as the microstructural organization of reconstructed fiber tracts, used for interhemispheric communication between different brain regions. Specifically, for neurophysiological function, we investigated the interhemispheric projections from dorsolateral prefrontal cortex (DLPFC) and PMd, both being highly involved in bimanual movement (Debaere et al., 2004; for review, see Swinnen and Gooijers, 2015; Beets et al., 2015), to contralateral M1 using the dual-site TMS (dsTMS) IHI paradigm (Mochizuki et al., 2004; Bäumer et al., 2006; Koch et al., 2006; O’Shea et al., 2007; Hinder et al., 2012). We used diffusion-based fiber tractography to quantify the microstructural organization of tracts connecting DLPFC and PMd with contralateral M1. This multimodal approach allowed us to elucidate neurophysiological function, structure, and behavior. We specifically focused on the preparation of complex bimanual movements as older adults demonstrate declined preparatory processes (Sterr and Dean, 2008), causing suboptimal execution (Hallett, 2000). We predicted that the extent of task-related modulation in IHI from DLPFC and PMd to contralateral M1 would be reduced in older adults relative to young adults as a result of the less coherent white matter microstructure of the interhemispheric fiber tracts connecting those regions, resulting in bimanual performance deficits in older adults.

\section{Materials and Methods}

Participants. Groups of healthy young ( $n=15,7$ males, age 22.6 years, SD 2.6 years) and older adults $(n=15,9$ males, age 66.0 years, SD 3.4 years) participated in the study. The Edinburgh Handedness Questionnaire (Oldfield, 1971) revealed that all participants were strongly right-handed (>95). All older participants were screened for cognitive impairments using the Montreal Cognitive Assessment (Nasreddine et al., 2005), revealing scores within the normal range $(\geq 26)$. Participants were further screened, checking exclusion criteria for TMS, which were adopted from Rossi et al. (2009). We also applied exclusion criteria for MRI studies, referring to the checklist formulated by the local hospital (UZ Leuven). Participants did not have any known neurological or psychiatric disorders. In addition, the MRI scans were checked for abnormalities. MR images were examined by a certified clinical MRI expert (S. Sunaert) to screen for any abnormalities. The protocol was in accordance with the Declaration of Helsinki (1964) and was approved by the local ethical committee of KU Leuven, Belgium (Project S51615). Participants were financially compensated for participation and provided written informed consent before the experiment.

Bimanual tracking task (BTT). A complex bimanual visuomotor task (BTT) was used, for which the involvement of the DLPFC and PMd has been previously demonstrated (Sisti et al., 2011, 2012; Gooijers et al., 2013; Beets et al., 2015). To identify the specific contribution of these brain regions for the control of the respective hand movements, we compared iso (1:1) and two noniso interhand frequencies with conversing frequency arrangements ( $3: 1$ and 1:3, i.e., left hand three times faster than right hand, and vice versa). The goal of the BTT was to accurately track a moving target presented on a screen with a cursor by rotating dials (Sisti et al., 2011, 2012; Gooijers et al., 2013; Beets et al., 2015). Participants were comfortably seated on a chair with both arms placed on a table situated in front of them. The palms faced down on palm rests and the elbows were bent at $\sim 135^{\circ}$. The palm rests were designed to help relaxing the hand muscles and to assure freedom of the index finger movements throughout the experiment. Participants were asked to place their index finger in a small groove to position the fingertip (diameter of $1.5 \mathrm{~cm}$ ) in the dial (diameter of $5 \mathrm{~cm}$ ), which was situated $\sim 60 \mathrm{~cm}$ in front of them (Fig. 1A). The left $(\mathrm{L})$ and right $(\mathrm{R})$ dial rotations were associated with the movements of the cursor on the ordinate and abscissa, respectively. The current setup was adapted from the previously used version (Beets et al., 2015) to maximize its suitability for a TMS protocol. Specifically, participants were instructed to move only their index fingers to manipulate rotating dials because the corticospinal projection to the primary mover of the index fingers (i.e., first dorsal interosseus [FDI] muscles) was targeted with TMS (for more details, see TMS procedure and EMG recording). A PC screen situated at a distance of $\sim 80 \mathrm{~cm}$ from the participants displayed visual stimulation and online feedback. During the experiment, participants' hands were covered to direct their attention to the PC screen.

A BTT trial started with a display of a blue target line (target template $[\mathrm{TT}]$ ), which was presented until the end of the trial (Fig. 2A). Two seconds after the onset of TT, an auditory imperative stimulus (IS, 525 $\mathrm{Hz}$ ) was presented for $126 \mathrm{~ms}$. Concurrently with IS, a white target dot started to move along the target line from the start to end position at a constant speed (duration $7 \mathrm{~s}$ ). Participants traced the moving white dot along a target line by simultaneous cyclical rotation of two dials with the left and right index fingers. Concurrent visual feedback was provided by means of a red cursor displaying the actual tracking trajectory based on the coordination between both fingers. Participants were required to rotate the dials clockwise with same (isofrequency) or different interhand frequency (nonisofrequency) ratios and with a different task allocation to each hand (1:1, 1:3, 3:1) (Fig. 2B). The size of the TT, target dot, and a red cursor corresponded to $162,0.19$, and 0.58 virtual units, respectively. The latter ratio indicates the relative speed of each hand compared with the other hand. As such, 1:3 indicated that the right hand is required to move three times faster than the left hand, whereas 3:1 indicates that the left hand is required to move three times faster than the right hand. Intertrial interval was set at $3 \mathrm{~s}$. 
Kinematic analyses. The positions $(x, y)$ of the target dot and cursor, which represents participant's kinematics, were sampled at 100 $\mathrm{Hz}$ and analyzed using Labview (8.5) software (National Instruments). Accuracy of tracking movement was assessed by a measure of target error in virtual units, which was obtained every $10 \mathrm{~ms}$ by measuring the mean Euclidean distance between the target and the cursor position at each point in time at each non-TMS trial. This measure is sensitive to detect any delays in movement onset. Preliminary analyses demonstrated that the anticipatory taskrelated modulations of projections from bilateral DLPFC and left PMd predicted the successful performance of the nonisofrequency (3:1 and 1:3) coordination tasks for up to $2 \mathrm{~s}$ into the trial, showing significant correlations between changes in IHI during the preparatory period and subsequent behavioral performance for both young and older adults $(p s<$ 0.05 ). As such, we focused on the target error for the time period between 0 and $2 \mathrm{~s}$ in a trial.

Image acquisition. A Philips Ingenia 3T CX MRI scanner with standard head coil was used for image acquisition. For all subjects, a highresolution T1-weighted structural image was acquired using MPRAGE $(\mathrm{TR}=2300 \mathrm{~ms}$, $\mathrm{TE}=2.98 \mathrm{~ms}, 1 \times 1 \times 1.1 \mathrm{~mm}^{3}$ voxels, field of view $=240 \times 256 \mathrm{~mm}^{2}, 160$ sagittal slices) for anatomical detail.

Multishell diffusion tensor images were acquired using the following parameters: singleshot spin-echo; slice thickness $=2.5 \mathrm{~mm}$, $\mathrm{TR}=8700 \mathrm{~ms}, \mathrm{TE}=116 \mathrm{~ms}$, number of diffusion directions $=150$, number of sagittal slices $=58$, voxel size $=2.5 \times 2.5 \times 2.5 \mathrm{~mm}^{3}$. Diffusion weightings of $b=0,700,1000$, and $2800 \mathrm{~s} / \mathrm{mm}^{2}$ were applied along $7,25,40$, and 75 uniformly distributed directions (Poot et al., 2010), respectively. Each series of diffusionweighted images was preceded by $a b=0 \mathrm{im}$ age. An additional 7 non-diffusion-weighted images were acquired, yielding $10 \mathrm{~b}=0$ images in total.

Diffusion-weighted image processing and probabilistic tractography. The diffusion data were preprocessed using the FMRIB (Functional MRI of the Brain) Software Library, FSL (Oxford University, Oxford, United Kingdom; www.fmrib.ox.ac.uk/fsl). Before processing, using Explore DTI (Leemans et al., 2009), we visually inspected each diffusionweighted imaging volume at high frame rate to identify visible artifacts in the data, such as large signal dropouts and geometric distortions (Gooijers et al., 2014). Following a recent recommendation (Tournier et al., 2011), the images were inspected in different "orthogonal" views to observe any interslice and intravolume instabilities (i.e., the "zebra pattern" or "zipper" artifact). After the visual inspection, for each subject, the diffusion-weighted volumes were aligned to its corresponding nondiffusion-weighted (b0) image. Following Fan et al. (2014), the diffusion data were concatenated across different shells and corrected jointly for eddy-current-induced geometric distortions. The gradient direction table was adjusted to account for rigid transformations resulting from motion and eddy current corrections.

Cortical seed masks. Using FSL, cortical seed masks necessary for probabilistic tractography were created in MNI space and transformed. The middle frontal gyrus (MFG) was extracted from the Harvard-Oxford Cortical Structural Atlas, provided with FSL. The most anterior half of the MFG was determined as the DLFC (Smith et al., 2004). For M1 and PMd, we used the Human Motor Area Template (http://lrnlab.org/) (Mayka et al., 2006). We also created a mask for the CC using the JHU ICBM DTI-81 atlas (Mori et al., 2008). Using the FMRIB's Diffusion

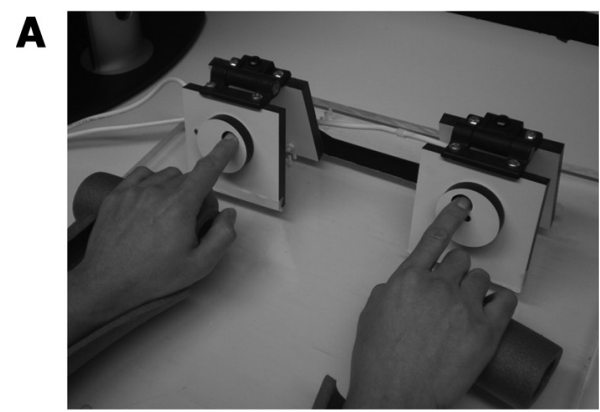

A, Experimental setup. The palm and arm rests were provided for increasing comfort. The palm rests are designed to rexing hand muscles and to assure freedom of the index finger movements throughout the experiment. The hands and dials (i.e., right to left and left to right hemisphere). Each direction consisted of 6 experimental blocks. Black coil represents test stimulation (TS). Gray coil represents conditioning stimulation (CS). DLPFC, dorsolateral prefrontal cortex; PMd, dorsal premotor cortex; M1, primary motor cortex; ISI, interstimulus interval.

Toolbox, the diffusion tensor model was fit to the data, from which fractional anisotropy (FA) images were obtained. The individual FA images were processed with tract-based spatial statistics (Smith et al., 2006) part of FSL (Smith et al., 2004). Using a nonlinear registration, all subjects' FA images were registered to common space (FMRIB58_FA) provided by FSL. The inverse of the registrations generated during the previous step was used to warp the seed masks to subject spaces.

Probabilistic tractography. Tractography between regions of interest (ROI) was performed with the MRtrix software package (Brain Research Institute, Melbourne, Australia; http://www.brain.org.au/software). From the each individual eroded FA map, a mask of predominantly single fiber voxels was extracted by choosing only strongly anisotropic $(\mathrm{FA}>0.7)$ voxels to estimate the spherical-harmonic coefficients of the response function (Tournier et al., 2004, 2008). Then, using MRtrix the fiber orientation distribution (FOD) was estimated at a whole-brain level by spherical deconvolution of the diffusion-weighted signal assuming that the diffusion-weighted signal measured from any fiber bundle is adequately described by a single response function (Tournier et al., 2004). This method has shown to provide FOD estimates that are robust to noise while preserving angular resolution and allowing tracking in regions of crossing fibers (Tournier et al., 2007). Constrained spherical deconvolution (CSD) was then performed based on the response function (Tournier et al., 2007). CSD reflects the distribution of fiber orientations within a given voxel and sufficiently circumvents the issue of crossing fibers inherent in the diffusion tensor model, resulting in improved tract reconstructions (Tournier et al., 2004, 2008). CSD was performed with the maximum harmonic order set to 8. Subsequently, probabilistic fiber tracking was conducted to eliminate the following 


\section{Preparatory period}

A

Target template (TT)

Start!

D) Imperative signal (IS)

C
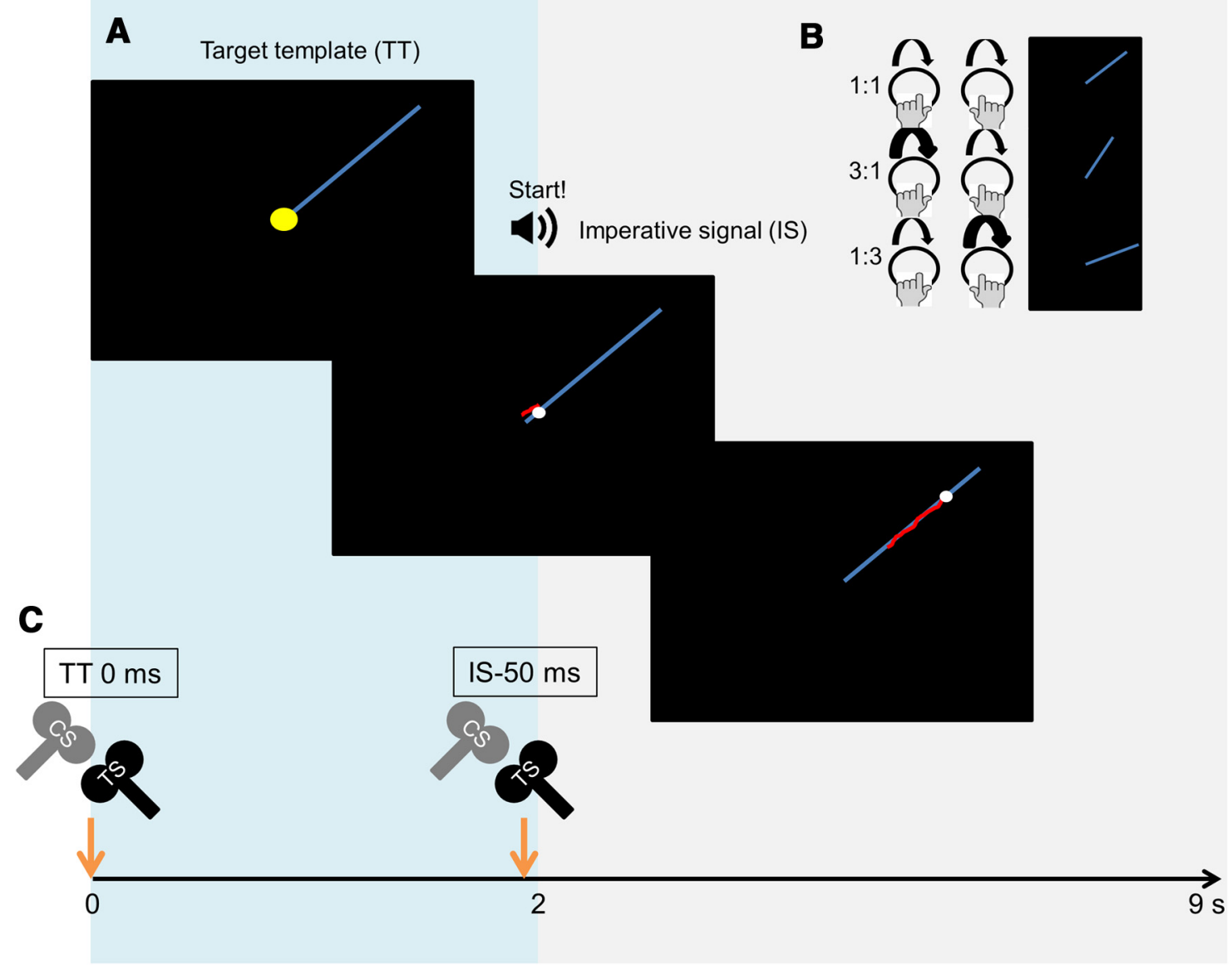

\section{Execution period}

Figure 2. A, A trial of the BTT starts with a display of a blue target line (TT), which was presented for an entire trial. An auditory IS (525 Hz, $126 \mathrm{~ms}$ ) was presented $2000 \mathrm{~ms}$ (preparatory phase) after the onset of TT. Concurrently with IS, a white target dot started to move along the target line from the starting (middle of the screen) to the end of the TT at a constant speed (duration $=7000$ ms). Participants were required to trace the moving white dot along a target line by simultaneous cyclical rotation of two dials with left and right index fingers. Concurrent visual feedback was provided by means of a red cursor displaying the actual tracking trajectory based on the contribution of both limbs. $\boldsymbol{B}$, Participants were required to rotate the dials clockwise with same or different interhand frequency ratios (1:1, 1:3, 3:1) to be able to follow the target template (blue line). The angle of the blue line denotes the frequency ratio. For example, 1:3 notation indicates that the right hand is required to move three times faster than the left hand. C, The modulation of interhemispheric interactions between the DLPFC and contralateral primary motor cortex (M1), dorsal premotor and contralateral $\mathrm{M} 1$, and $\mathrm{M} 1$ and $\mathrm{M} 1$ during movement preparation were investigated. In a trial, the test stimulus was delivered either at the onset of the target template (TT0 $\mathrm{ms}$ ) or at $50 \mathrm{~ms}$ before the onset of the auditory imperative signal (IS-50 ms), whereas the conditioning stimulus was applied to DLPFC, PMd, or M1 before TS with a designated IHI (i.e., $60 \mathrm{~ms}$ for DLPFC, 8 or $40 \mathrm{~ms}$ for PMd, and 10 or $40 \mathrm{~ms}$ for $\mathrm{M} 1)$.

tracts based on an algorithm which uses the fiber orientation at each step: (1) left DLPFC-right M1, (2) right DLPFC-left M1, (3) left PMd-right M1, (4) right PMd-left M1, (5) left M1-right M1, and (6) right M1-left $\mathrm{M} 1$ restricting tracts passing the CC. As such, any tracts connecting these cortical regions via the CC were included in the reconstructed tracts. Importantly, this procedure does not exclude pathways passing via subcortical structures. We visually inspected the cortical seed masks and confirmed that the individual target coordinates used for our TMS experiments (see TMS procedure and EMG recording) were included in the masks. The parameters for the algorithm were a step size of $0.2 \mathrm{~mm}$, a radius curvature of $1 \mathrm{~mm}$, maximum track length of $200 \mathrm{~mm}$, and an FOD cutoff value of 0.1 . Finally, a tracts density image was created for each tract for further analysis. Mean FA values for each interhemispheric tract were obtained by averaging FA values for all voxels, which were included in each tract, using the mrstats function in MRtrix. The FiberNavigator (Chamberland et al., 2014) was used for visualization.

TMS procedure and EMG recording. We used a dual-site (ds)TMS paradigm (Ferbert et al., 1992) to investigate IHI from DLPFC and PMd to contralateral M1 as well as between M1s in both directions (i.e., left to right and right to left). The dsTMS paradigm was designed to investigate interhemispheric communication via fibers of the CC (Gerloff et al., 1998; Gazzaniga, 2005), which is essential for the performance of bimanual movement (for a review, see Gooijers and Swinnen, 2014). For the successful performance of temporally and/or spatially different bimanual movements (such as polyrhythmic bimanual tapping), it is essential to suppress the more intrinsic (in-phase) coordination mode. Interhemispheric interactions are assumed to play a critical role in this regulatory process (Geffen et al., 1994). We investigated the projections from DLPFC and PMd to M1 in both directions (i.e., left to right hemisphere and vice versa) as well as the bidirectional M1-M1 interaction as a control condition to obtain a comprehensive picture of the role of these brain regions in the preparation of bimanual movements (Fig. 1B).

IHI measurement was performed with two monophasic Magstim 200 units (Magstim), each connected to a figure-of-eight coil (50 $\mathrm{mm}$ outer diameter of each wing). For M1 stimulation, the coil was tangentially placed over the optimal position (hotspot) of the head to induce a posterior-anterior current flow and to elicit motor evoked potentials (MEPs) in the FDI muscle. EMG surface electrodes $(\mathrm{Ag} / \mathrm{AgCl})$ were placed over the FDI in both hands with a belly-tendon montage. Signals were amplified with a gain of 1000 , bandpass filtered $(10-500 \mathrm{~Hz})$, and 
sampled at $2000 \mathrm{~Hz}$ a using MESPEC 8000 EMG system (Mega Electronics) for offline analysis. The individual resting motor threshold (rMT) was determined as the lowest stimulus intensity that produced MEPs of $>50 \mu \mathrm{V}$ in the right and left FDI muscles in at least three of five consecutive trials when stimulating at the predetermined hotspots. To ensure TMS was precisely targeted on the desired stimulation area, a highresolution structural T1-weighted anatomical image of each subject (Philips Ingenia 3.0T CX, repetition time/echo time $=9.6 / 4.6 \mathrm{~ms}$, inversion time $=900 \mathrm{~ms}$, field of view $=250 \mathrm{~mm}$, flip angle $=8^{\circ}$, matrix $=$ $256 \times 256$, voxel size $1.0 \times 1.0 \times 1.0 \mathrm{~mm}$ ) was coregistered with the fiducial landmarks using a neuronavigation system (Visor 2, ANT Neuro). The location of DLPFC was identified following Mylius et al. (2013). First, the MFG was established, which was bordered by the anterior border of MFG, superior frontal sulcus (SFS), inferior frontal sulcus (IFS), and precentral sulcus (PCS). Second, the MFG was divided equally into three parts and the separating line between the anterior and middle thirds of the MFG was defined as DLPFC (for more details, see Mylius et al., 2013). PMd was defined as being located immediately anterior to PCS and adjacent to the dorsal bank of SFS (Duque et al., 2012). This area likely corresponds to the caudal part of the dorsal premotor cortex (F2, PMdc) in monkeys (Fink et al., 1997; Picard and Strick, 2001). This part of premotor cortex has been associated with movement preparation (Picard and Strick, 2001). The mean \pm SD values of Talariach coordinates are as follows: young adults, left DLPFC, $x=-38.0 \pm 4.8, y=$ $36.7 \pm 4.8, z=34.9 \pm 3.9$; right DLPFC: $x=37.5 \pm 2.4, y=37.7 \pm 5.2$, $z=31.3 \pm 4.6$; left PMd: $x=-30.2 \pm 2.2, y=-2.4 \pm 6.3, z=54.0 \pm$ 1.3; right PMd: $x=29.4 \pm 3.2, y=-3.6 \pm 5.9, z=55.1 \pm 2.2$; older adults, left DLPFC, $x=-33.5 \pm 3.5, y=37.8 \pm 6.2, z=30.2 \pm 8.2$; right DLPFC: $x=33.6 \pm 5.6, y=38.5 \pm 7.5, z=33.1 \pm 7.7$; left PMd: $x=-31.7 \pm 5.4, y=1.6 \pm 4.5, z=51.5 \pm 4.6$; right PMd: $x=31.7 \pm 4.4$, $y=-1.8 \pm 7.7, z=52.1 \pm 5.7$, as estimated at the cortical surface. There were no group differences in any of the coordinates which were examined by independent $t$ tests $(p>0.10)$.

For the assessment of IHI, we used the dsTMS paradigm. The dsTMS paradigm initially evolved to investigate IHI between homolog M1s (Ferbert et al., 1992). The protocol involves the delivery of a conditioning stimulation (CS) to one hemisphere before the delivery of a testing stimulation (TS) to the other hemisphere at interstimulus intervals (ISIs) of 6-60 ms (Ferbert et al., 1992; Ni et al., 2009). It is assumed that IHI with short ISI $(\leq 10 \mathrm{~ms})$ is mediated by postsynaptic $\mathrm{GABA}_{\mathrm{A}}$ mechanisms, whereas $\mathrm{GABA}_{\mathrm{B}}$-ergic circuits are responsible for IHI with long ISI ( $\geq 40$ ms) (Chowdhury et al., 1996; Sanger et al., 2001; Irlbacher et al., 2007).

For M1-M1 and PMd-M1, two ISIs were applied to investigate short (SIHI) and long IHI (LIHI). For PMd-M1 IHI, 8 and 40 ms ISIs were used, whereas for M1-M1, 10 and 40 ms ISIs were used to assess SIHI and LIHI, respectively (Hinder et al., 2012). For DLPFC-M1 interaction, a 60 ms ISI was used to assess only LIHI, as SIHI appeared to be absent in DLPFC-M1 interaction (Ni et al., 2009). The TS intensity was set to elicit an MEP of $\sim 1 \mathrm{mV}$ (peak-to-peak) for the FDI muscle in each hand during rest. The CS intensities were set to $110 \%$ rMT for M1 and PMd (Kroeger et al., 2010; Hinder et al., 2012), whereas 140\% rMT was used to stimulate DLPFC (Ni et al., 2009; Uehara et al., 2013).

Procedure. All participants first underwent an MRI session followed by three TMS experimental sessions to assess IHI during the performance of BTT. The order of TMS sessions was counterbalanced across participants. For each TMS session, one of the three types of interhemispheric interaction (DLPFC-M1, PMd-M1, or M1-M1) was examined on different days with at least $48 \mathrm{~h}$ between sessions. In each session, interhemispheric interaction from both left to right $(\mathrm{L} \rightarrow \mathrm{R})$ and right to left $(\mathrm{R} \rightarrow \mathrm{L})$ hemisphere was investigated using dsTMS.

In each TMS session, we determined rMT and the stimulus intensity that is necessary to evoke an MEP amplitude of $\sim 1 \mathrm{mV}$ for each hemisphere. Then we ran two blocks of baseline IHI assessment consisting of 12 TS and 12 CS-TS trials at each ISI (only for PMd-M1 and M1-M1) at rest. In each block, one of the directions (i.e., from both left to right and right to left hemisphere) was tested. Thus, a total of 36 TMS trials per block for PMd-M1 and M1-M1 interaction were administered at rest (i.e., 12 TS trials, 12 CS-TS trials for SIHI, and 12 CS-TS trials for LIHI), whereas a total of 24 trials per block was conducted for the assessment of
DLPFC-M1 interaction (i.e., 12 TS trials and 12 CS-TS trials for LIHI). Additionally, at the beginning of each session, participants performed 12 practice trials for each movement frequency condition $(1: 1,1: 3,3: 1)$ without TMS delivery before the main IHI experimental trials.

We conducted 12 experimental blocks consisting of 6 consecutive blocks assessing IHI from left to right hemisphere and 6 consecutive blocks assessing IHI from right to left hemisphere. The order of the direction of interaction (i.e., left to right and right to left) was counterbalanced across participants. Within each direction of interaction, participants performed 2 blocks of 3 different movement frequency conditions. For optimal preparation, each block consisted of the same interhand frequency and the order of the blocks was counterbalanced across participants. Each experimental block consisted of 38 trials for PMd-M1 and M1-M1 interactions with two ISIs or 26 trials for DLPFC-M1 interaction with single ISI. PMd-M1 and M1-M1 interactions (i.e., 38 trials) consisted of the delivery of 12 TS, 12 CS-TS, with short ISI ( 8 ms for PMd and $10 \mathrm{~ms}$ for M1), 12 CS-TS with long ISI ( $40 \mathrm{~ms}$ ), and additional two non-TMS trials assessing BTT performance in the absence of TMS. For DLPFC-M1 interaction, we only assessed long ISI ( $60 \mathrm{~ms})$, thus resulting in 26 trials. The time point of the TMS delivery was either at the onset of the target template (TT0 ms) or $50 \mathrm{~ms}$ before the onset of the imperative signal (IS-50 ms) in a trial (Fig. $2 C$ ). The first time point (TT0 ms) was to obtain a baseline measurement of IHI during the preparatory period. The second time point, occurring $50 \mathrm{~ms}$ before the IS (IS-50 ms), was chosen because the movement-related preparatory effect on the contralateral M1 is likely to be most obvious when closely approaching the movement onset. Accordingly, over two blocks, each movement frequency yielded 12 TS and 12 CS-TS (with each ISIs for PMd-M1 and M1-M1) at each TMS time point. Rest $(5 \mathrm{~min})$ between blocks was provided to avoid fatigue.

Data processing and analysis. Mean FA values were calculated for the assessment of microstructural organization for each tract (i.e., mean tract FA). FA is a rotationally invariant index, which ranges between 0 (isotropic) to 1 (anisotropic). FA values have been widely used as a measure of the magnitude and orientation of water diffusion based on eigenvalues in the diffusion tensor (Pierpaoli and Basser, 1996). Accordingly, higher FA values imply a greater degree of anisotropic motion of water molecules and are thought to reflect a better organization of white matter (WM) microstructure (Basser and Pierpaoli, 1996).

Corticospinal excitability was determined as the average peak-to-peak MEP in the FDI muscles in a time window of 20-100 ms following TS only trials. MEPs were subsequently averaged across all trials at each movement frequency condition $(1: 1,1: 3,3: 1)$, at each time point (TT0 $\mathrm{ms}$, IS-50 ms), and for each participant. Interhemispheric interactions (referred to as IHI) were determined as the average MEP amplitude (determined as described above) in CS-TS trials, relative to the average MEP amplitude in response to TS (i.e., $\mathrm{IHI}=\mathrm{MEP}_{\mathrm{CS}-\mathrm{TS}} / \mathrm{MEP}_{\mathrm{TS}}$ ). Trials in which root mean square EMG exceeded $10 \mu \mathrm{V}$ (Carson et al., 2004) during the $40 \mathrm{~ms}$ immediately preceding the TMS pulse were discarded.

In presenting the results, the data are expressed as mean $\pm 95 \%$ CIs. Mean target error scores for BTT were analyzed by a 2 [group] $\times 3$ [session, 1, 2, 3] $\times 3$ [ratio, 1:1, 1:3, 3:1] repeated-measures ANOVA. FA value was analyzed by a 2 [group] $\times 2$ [hemisphere: left, right] $\times 3$ [tracts: DLPFC1-M1, PMd-M1, M1-M1] repeated-measures ANOVA. rMTs and $1 \mathrm{mV}$ TS intensity, expressed as a percentage of maximum stimulator output were examined by 2 [group] $\times 2$ [hemisphere: left, right] $\times 3$ [session: $1,2,3$ ] repeated-measures ANOVAs.

MEP at rest was analyzed by a 2 [group] $\times 2$ [hemisphere: left, right] $\times$ 3 [session: 1, 2, 3] repeated-measures ANOVA, whereas ratio (1:1, 1:3, 3:1) and time (TT0 ms, IS-50 ms) were additionally included as independent variables for the analysis of MEP. We included session as a factor to investigate whether there were any changes in corticospinal excitability over sessions.

Interaction between DLPFC and M1 at rest was analyzed by a 2 [group] $\times 2$ [direction of interaction: $\mathrm{R} \rightarrow \mathrm{L}, \mathrm{L} \rightarrow \mathrm{R}$ ] repeatedmeasures ANOVA, whereas the additional factor ISI [short and long] was included for the analyses of PMd-M1 and M1-M1 interactions at rest. Task-related changes in interactions between different cortical areas were analyzed separately as DLPFC-M1 yielded only one ISI, 
whereas we investigated two ISIs (short and long) for PMd-M1 and M1-M1 interactions. As such, IHI for DLPFC-M1 was analyzed by a 2 [group] $\times 2$ [direction of interaction: $\mathrm{R} \rightarrow \mathrm{L}, \mathrm{L} \rightarrow \mathrm{R}$ ] $\times 3$ [ratio: $1: 1$, $1: 3,3: 1] \times 2$ [time: TT0 ms, IS-50 ms] repeated-measures ANOVA, whereas ISI (short, long) was included for the analyses of PMd-M1 and M1-M1 interactions.

If the sphericity assumption was violated, Greenhouse-Geisser's degrees of freedom adjustment was applied to the critical $p$ values. Newman-Keuls post hoc procedure was used to explore significant main and interaction effects. The level of significance was set at $p<0.05$. Partial $\eta$ squared $\left(\eta_{\mathrm{p}}^{2}\right)$ values are provided as measure of effect size, where appropriate. Cutoffs $\geq 0.01$ small, $\geq 0.06$ medium, and $\geq 0.14$ large were applied for $\eta_{\mathrm{p}}^{2}$ (Sink and Stroh, 2006).

The relationships between brain function, structure, and bimanual performance were examined with correlation analyses for each age group separately. As mentioned above (see Kinematic analyses), the preliminary analyses correlating IHI modulations and BTT target error revealed that IHI modulations in bilateral DLPFC and left PMd to contralateral M1 during preparation of bimanual movement significantly predict successful nonisofrequency performance up to $2 \mathrm{~s}$ into a trial in both young and older adults. Accordingly, Pearson product moment correlation coefficients between IHI change score (IHI at IS-50 ms/IHI at TT0 ms, i.e., values $>1$ indicate disinhibitory change and values $<1$ indicate inhibitory change during the preparatory period) and target error during the initial $2 \mathrm{~s}$ into movement execution (obtained in the corresponding trials) was obtained to investigate the relationship between brain function and behavior. Similarly, to evaluate the association between brain structure and behavior, FA value in each tract was correlated with target error during the initial $2 \mathrm{~s}$, which was obtained from the TMS session, assessing the particular interaction. Furthermore, if significant bivariate correlations were evident between FA value and target error, these relationships were subjected to partial correlation analyses to investigate the association between brain structure (FA value) and behavior (BTT target error) by controlling for the effect of function (IHI modulation). Finally, we also assessed the relationship between brain structure and function obtaining correlation coefficients between FA value and corresponding IHI modulation. Bonferroni corrections were applied for all correlation analyses to control for Type I error. Because there were three conditions (i.e., $1: 1,3: 1,1: 3)$ in the BTT, $\alpha$ level was set at $0.017(0.05 / 3$, critical $r=0.57)$ for correlation analyses using BTT (i.e., FA vs BTT and IHI vs BTT). For correlation analyses between mean FA values and IHI modulations, $\alpha$ level was set at $0.017(0.05 / 3$, critical $r=0.57)$ for DLPFC-M1 (IHI was obtained in three different movement conditions), whereas $\alpha$ level was set at $0.008(0.05 / 6$, critical $r=0.61)$ for PMd-M1 and M1-M1 as we tested two ISIs (SIHI and LIHI) for these interactions.

\section{Results}

As the primary interest of the current study concerns age-related effects, significant main effects and interactions involving group are described in detail.

\section{BTT performance}

BTT performance was assessed examining target error across a $0-2$ s time window during movement execution. Significant main effects of group $\left(F_{(1,28)}=40.35, p<0.001, \eta_{\mathrm{p}}^{2}=0.59\right)$ and ratio $\left(F_{(2,56)}=41.89, p<0.001, \eta_{\mathrm{p}}^{2}=0.35\right)$ were best interpreted via a significant interaction of group $\times$ ratio $\left(F_{(2,56)}=10.31, p<\right.$ $\left.0.001, \eta_{\mathrm{p}}^{2}=0.27\right)$. As shown in Figure 3, age differences were evident at the nonisofrequency mode, whereas older adults showed comparable performance with young adults at isofrequency conditions. In older adults, not only nonisofrequency conditions (3:1 and 1:3) showed higher error than the isofrequency condition. Within the nonisofrequency conditions, the 3:1 condition was more difficult to perform (higher error) than the $1: 3$ condition. There was no significant main effect of session $\left(F_{(2,56)}=0.94, p=0.40, \eta_{\mathrm{p}}^{2}=0.03\right)$, indicating that performance during the initial $2 \mathrm{~s}$ time window did not improve over sessions.

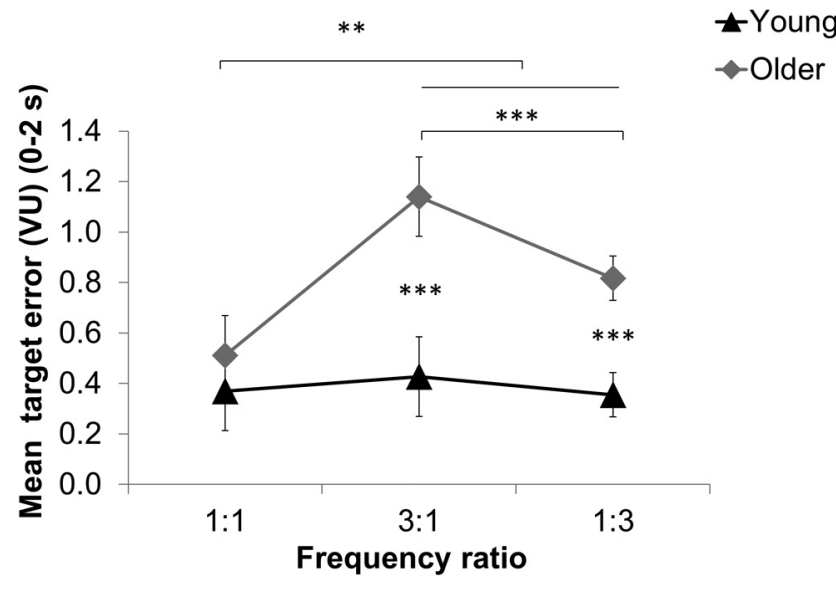

Figure 3. Mean target error score for each movement frequency ratio between 0 and 2 s time window of movement execution in young and older adults. Error bars indicate $95 \%$ Cls. ${ }^{*} p<$ 0.05. ${ }^{* *} p<0.01$. ${ }^{* * *} p<0.001$.

\section{MRI measure}

Trajectories from DLPFC, PMd, and M1 to contralateral M1 were successfully reconstructed in all subjects, using probabilistic tractography (Fig. 4). With respect to the possible pathway connecting DLPFC and contralateral M1, it has been suggested that neural input from the DLPFC likely reaches the contralateral M1 either via ipsilateral M1 or via homologous DLPFC transcallosally and then to the contralateral M1 (Ni et al., 2009). We opted not to apply exclusion masks on either homologous DLPFC or ipsilateral M1 to identify possible pathways because (1) the main research question in the current study was to identify the relationships between brain structure, neurophysiological function, and behavior in older adults; and (2) IHIs assessed with TMS cannot dissociate these different pathways anyway. Our reconstructed interhemispheric fiber tracts strongly supported the latter case (e.g., left DLPFC-right DLPFC-right M1) showing abundant interhemispheric fiber tracts (Kim et al., 2014) reaching homologous DLPFC first and subsequently ascending and entering M1 in the same hemisphere (Figs. 4, 5).

\section{FA}

To compare the microstructural organization between the age groups, mean FA values obtained from each interhemispheric fiber tract were examined. A significant main effect of group $\left(F_{(1,28)}=19.02, p<0.001, \eta_{\mathrm{p}}^{2}=0.40\right)$ revealed that mean FA value was significantly higher in young adults $(0.39 \pm 0.02)$ than older adults $(0.36 \pm 0.02)$, suggesting that the directional coherence of intracellular water diffusion declines with advancing age (Fig. 6). There was also a significant main effect of tracts $\left(F_{(2,56)}=\right.$ $\left.60.46, p<0.001, \eta_{\mathrm{p}}^{2}=0.68\right)$, suggesting that the mean FA value in DLPFC-M1 tract was significantly lower $(0.35 \pm 0.02)$ relative to PMd-M1 $(0.39 \pm 0.02)$ and M1-M1 tracts $(0.40 \pm 0.02)(p<$ $0.001)$. There were no other significant main effects and interactions $\left(F<2.38, p>0.10, \eta_{\mathrm{p}}^{2}<0.08\right)$.

\section{TMS measures: resting motor threshold and $1 \mathrm{mV}$ TS}

For rMT, a significant main effect of group $\left(F_{(1,28)}=6.73, p=\right.$ $\left.0.01, \eta_{\mathrm{p}}^{2}=0.19\right)$ suggested that older adults showed significantly higher $\operatorname{rMT}(47.99 \pm 1.34)$ than young adults $(42.61 \pm 1.26)$ across sessions and hemispheres. Similarly, a significant main effect of group at $1 \mathrm{mV}$ TS intensity $\left(F_{(1,28)}=10.40, p=0.01, \eta_{\mathrm{p}}^{2}\right.$ $=0.27$ ) revealed that higher TS intensity was required to evoke 1 $\mathrm{mV}$ in older adults $(57.40 \pm 1.48$; corresponding to $\sim 120 \%$ 


\section{Left to right hemisphere}

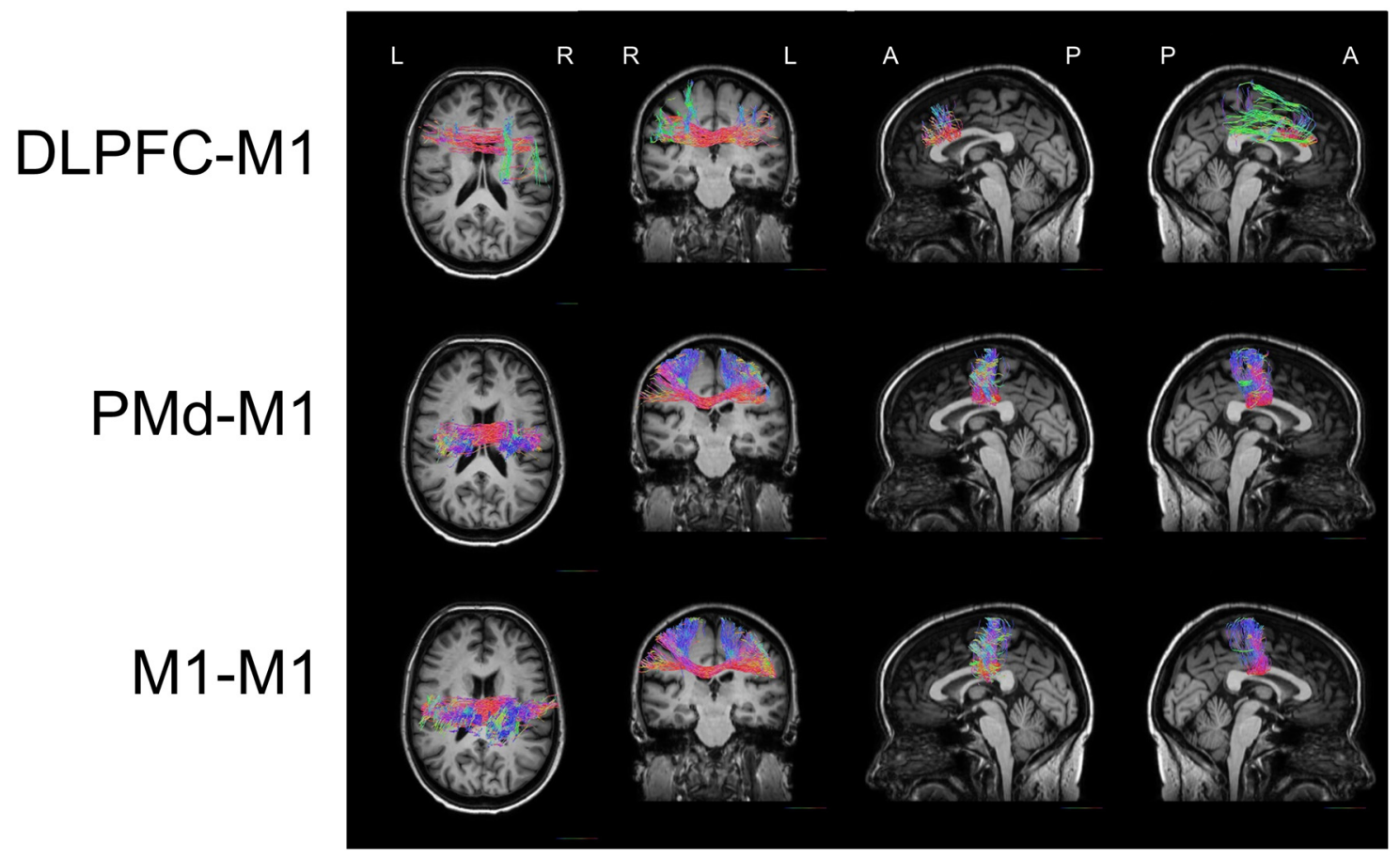

Figure 4. Reconstructed interhemispheric fiber tracts from the left to right hemisphere using probabilistic constrained spherical deconvolution (CSD) from a representative participant. The tracts are displayed on the participant's $\mathrm{T1}$ image. Color represents orientation of streamlines within each voxel: red represents left-right/right-left; blue represents superior-inferior/inferior-superior; green represents anterior-posterior/posterior-anterior. The FiberNavigator (Chamberland et al., 2014) was used for visualization.

\section{Right to left hemisphere}

\section{DLPFC-M1}

PMd-M1

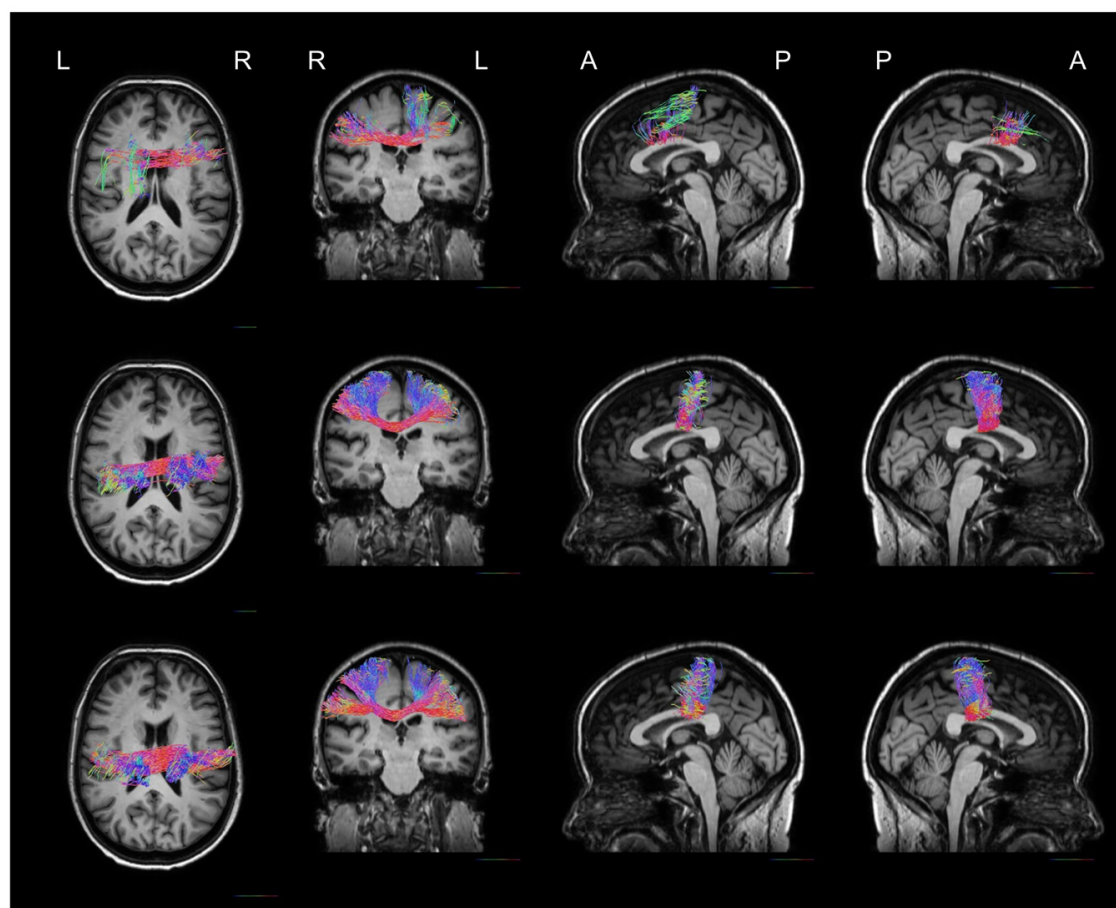

Figure 5. Reconstructed interhemispheric fiber tracts from the right to left hemisphere using probabilistic constrained spherical deconvolution (CSD) from a representative participant. The tracts are displayed on the participant's $\mathrm{T} 1$ image. Color represents orientation of streamlines within each voxel: red represents left-right/right-left; blue represents superior-inferior/inferior-superior; green represents anterior-posterior/posterior-anterior. The FiberNavigator (Chamberland et al., 2014) was used for visualization. 


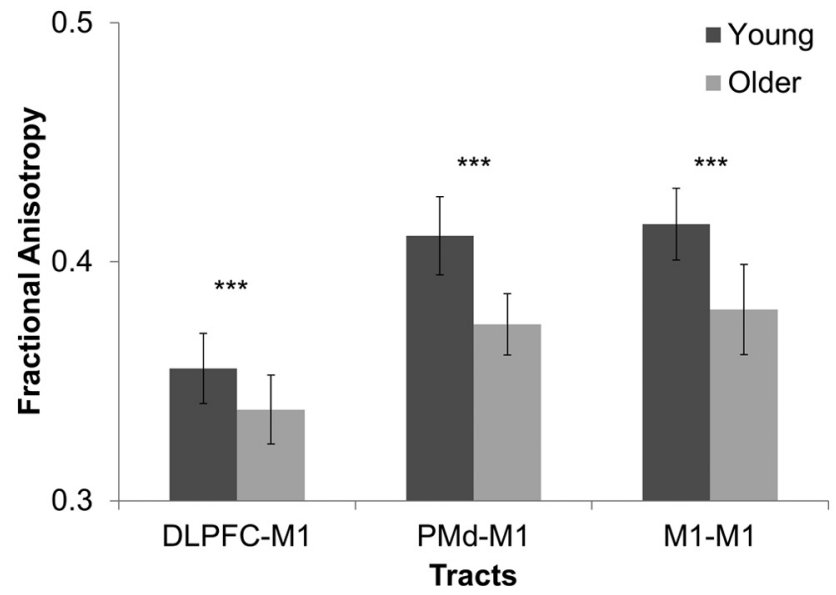

Figure 6. Mean $\mathrm{FA}$ in young and older adults. A main effect of group $\left(F_{(1,28)}=19.02, p<\right.$ $0.001, \eta_{\mathrm{p}}^{2}=0.40$ ) indicates that FA values are lower in older adults than young adults. Error bars indicate $95 \%$ Cls. ${ }^{* * *} p<0.001$.

rMT) relative to young adults $(49.02 \pm 1.48$; corresponding to $\sim 115 \% \mathrm{rMT}$ ). Importantly, for both rMT and $1 \mathrm{mV}$, TS main effects or interactions, including hemisphere and session, were not significant $\left(F<2.45, p>0.10, \eta_{\mathrm{p}}^{2}<0.08\right)$, suggesting that rMT and TS intensity did not vary across sessions or hemispheres in both young and older adults.

\section{Corticospinal excitability}

As expected, MEP corticospinal excitability of projections to left and right FDI at rest were not significantly different across groups, sessions, and hemispheres $\left(F<1.70, p>0.19, \eta_{\mathrm{p}}^{2}<\right.$ 0.06 ). This result, together with rMT and TS intensity, suggests that corticospinal projection at rest was stable across sessions.

Corticospinal excitability at TT0 ms and IS-50 ms during the movement preparation period were compared using MEP amplitude. There were no significant main effects and interactions involving hemisphere, session, time, or ratio $\left(F<1.55, p>0.20, \eta_{\mathrm{p}}^{2}\right.$ $<0.10$ ), indicating that corticospinal excitability was comparable across hemispheres, sessions, and frequencies. Importantly, ANOVA did not show a significant main effect of time $\left(F_{(1,28)}=\right.$ $\left.1.13, p=0.29, \eta_{\mathrm{p}}^{2}=0.04\right)$, suggesting that corticospinal excitability at TT0 $\mathrm{ms}(1.61 \pm 0.51 \mathrm{mV})$ was not different from IS-50 ms $(1.49 \pm 0.50)$ (Fig. 7). As such, any IHI modulations in the following analyses reflect changes in conditioned MEP.

\section{Interhemispheric interaction DLPFC-M1}

Overall, the DLPFC-M1 IHI at rest was inhibitory for both groups (young, $0.72 \pm 0.17$; older, $0.67 \pm 0.15$ ). The interaction between DLPFC and contralateral M1 at rest was analyzed by a 2 [group] $\times$ [direction of interaction: $\mathrm{R} \rightarrow \mathrm{L}, \mathrm{L} \rightarrow \mathrm{R}$ ] repeated-measures ANOVA. There were no significant main effects or interactions $\left(F<0.51, p>0.48, \eta_{\mathrm{p}}^{2}<0.02\right)$, suggesting that, at rest, IHIs between DLPFC and M1 were comparable across age groups and across directions $(\mathrm{R} \rightarrow \mathrm{L}, 0.68 \pm$ $0.16 ; \mathrm{L} \rightarrow \mathrm{R}, 0.71 \pm 0.16$ ).

We next examined task-related modulations in IHI between DLPFC and M1. We predicted that older adults would show a declined ability to modulate DLPFC-M1 IHI, which is likely to show disinhibitory changes during movement preparation of the complex conditions (1:3 and 3:1) because the DLPFC is involved in cognitive regulation of movement. Accordingly, IHI for DLPFC-M1 was analyzed by a 2 [group: young, older] $\times 2$ [direction of interaction: $\mathrm{R} \rightarrow \mathrm{L}, \mathrm{L} \rightarrow \mathrm{R}$ ] $\times 3$ [ratio: $1: 1,1: 3,3: 1] \times$
2 [time: TT0 ms, IS-50 ms] repeated-measures ANOVA. Significant main effects of ratio $\left(F_{(2,56)}=11.27, p<0.001, \eta_{p}^{2}=0.29\right)$ and time $\left(F_{(1,28)}=14.48, p<0.001, \eta_{\mathrm{p}}^{2}=0.34\right)$ and an interaction of group $\times$ time $\left(F_{(1,28)}=20.00, p<0.001, \eta_{p}^{2}=0.42\right)$ are best interpreted with reference to the significant interaction between group, ratio, and time $\left(F_{(2,56)}=8.04, p<0.001, \eta_{\mathrm{p}}^{2}=\right.$ 0.22 ). As shown in Figure 8 , in young adults, IHI showed disinhibitory changes from TT0 ms to IS-50 ms in 3:1 $(p<0.001)$ (Fig. $8 B)$ and $1: 3$ conditions $(p<0.001)$ (Fig. $8 C$ ), whereas the level of IHI was unchanged in the $1: 1$ condition (Fig. $8 A$ ) during the preparatory period of the task $(p=0.996)$. In contrast, these IHI modulations in nonisofrequency conditions were absent in older adults $(p>0.60)$ as we expected. There were no other significant main effects or interactions $\left(F<3.08, p>0.0 .6, \eta_{\mathrm{p}}^{2}<0.10\right)$.

PMd-M1

Overall, the DLPFC-M1 IHI at rest was inhibitory for both groups (young, $0.71 \pm 0.19$; older, $0.76 \pm 0.14$ ). PMd-M1 interaction at rest was analyzed by a 2 [group] $\times 2$ [direction of interaction: $\mathrm{R} \rightarrow \mathrm{L}, \mathrm{L} \rightarrow \mathrm{R}$ ] $\times 2$ [ISI: $8 \mathrm{~ms}, 40 \mathrm{~ms}$ ] repeatedmeasures ANOVA. There were no significant main effects or interactions $\left(F<1.50, p>0.23, \eta_{\mathrm{p}}^{2}<0.05\right)$, suggesting that, at rest, IHIs between PMd and M1 were comparable across age groups, across directions $(\mathrm{R} \rightarrow \mathrm{L}, 0.72 \pm 0.15 ; \mathrm{L} \rightarrow \mathrm{R}, 0.75 \pm 0.18)$, and across ISIs ( $8 \mathrm{~ms}, 0.77 \pm 0.15 ; 40 \mathrm{~ms}, 0.70 \pm 0.18$ ).

We predicted that older adults would show a reduced ability to modulate PMd-M1 IHI, in which the gating of motor output from the contralateral M1 in a task specific manner is manifested (e.g., disinhibitory modulation during movement preparation when the M1 needs to increase motor output). This hypothesis was tested with a 2 [group] $\times 2$ [direction of interaction: $\mathrm{R} \rightarrow \mathrm{L}$, $\mathrm{L} \rightarrow \mathrm{R}$ ] $\times 3$ [ratio: 1:1, 1:3, 3:1] $\times 2$ [ISI: $8 \mathrm{~ms}, 40 \mathrm{~ms}$ ] $\times 2$ [time: TT $0 \mathrm{~ms}$, IS-50 ms] ANOVA. A significant interaction of direction $\times$ ratio, $F_{(2,56)}=4.58, p<0.05, \eta_{\mathrm{p}}^{2}=0.14$ is best interpreted in view of the significant 3 -way interaction of direction $\times$ ratio $\times$ time $\left(F_{(2,56)}=4.59, p=0.014, \eta_{\mathrm{p}}^{2}=0.14\right)$. As illustrated in Figure 8, the interaction between right PMd and left M1 (Fig. 9B) showed no change during the preparatory period, regardless of the movement ratio, whereas task-related functional modulations in IHI were observed in the interaction between left PMd and right M1 (Fig. 9A). The left PMd-right M1 interaction became more disinhibitory in the $3: 1$ condition $(p=0.001)$, in which the left hand needs to move three times faster than the right hand. In contrast, the suppression of IHI was observed during the preparation of $1: 3$ coordination $(p=0.009)$. The level of IHI was unchanged for the preparation of isofrequency coordination $(p=0.36)$. These task-specific IHI modulations between the left PMd and right M1 likely reflect the left PMd's crucial role for the preparation of the complex bimanual action control. Specifically, it appears that the left PMd is gating the motor output from the right $\mathrm{M} 1$ in a functional manner (i.e., less output when the left hand needs to slow down in the 1:3 condition and vice versa in the 3:1 condition). There were no interactions including group as a factor $\left(F<3.14, p>0.09, \eta_{\mathrm{p}}^{2}<0.10\right)$, suggesting that PMd function was maintained in the older adults, contrary to our prediction.

\section{M1-M1}

Overall, the M1-M1 IHI at rest was inhibitory for both groups (young, $0.64 \pm 0.13$; older, $0.69 \pm 0.21$ ). Interaction between $\mathrm{M} 1 \mathrm{~s}$ at rest was analyzed by a 2 [group] $\times 2$ [direction of interaction: $\mathrm{R} \rightarrow \mathrm{L}, \mathrm{L} \rightarrow \mathrm{R}$ ] $\times 2$ [ISI: $10 \mathrm{~ms}, 40 \mathrm{~ms}$ ] repeated-measures ANOVA. There were no significant main effects or interactions 
$\left(F<0.65, p>0.43, \eta_{\mathrm{p}}^{2}<0.02\right)$, suggesting that at rest, IHIs between M1s were comparable across age groups, across directions $(\mathrm{R} \rightarrow \mathrm{L}, 0.64 \pm 0.13 ; \mathrm{L} \rightarrow \mathrm{R}, 0.69 \pm$ 0.22 ), and across ISIs (SIHI, $0.65 \pm 0.15$; LIHI, $0.68 \pm 0.20$ ).

Task-related modulation during movement preparation in view of the interaction between $\mathrm{M} 1 \mathrm{~s}$ was analyzed by a 2 [group] $\times 2$ [direction of interaction: $\mathrm{R}$ $\rightarrow \mathrm{L}, \mathrm{L} \rightarrow \mathrm{R}$ ] $\times 3$ [ratio: $1: 1,1: 3,3: 1] \times 2$ [ISI: $8 \mathrm{~ms}, 40 \mathrm{~ms}$ ] $\times 2$ [time: TT0 ms, IS-50 ms]. There were no significant main effects or interactions $(F<3.38, p>0.08$, $\left.\eta_{\mathrm{p}}^{2}<0.11\right)$.

\section{Association between brain structure, neurophysiological function, and behavior}

Brain structure and behavior: correlation between FA and BTT target error

In older adults, but not in young adults, significant negative correlations were found between BTT target error scores and FA values in all of the tracts originating from the left hemisphere but exclusively in the 3:1 condition (Table 1; Fig. 10A for DLPFC-M1 tracts; Fig. 11A for PMd-M1 tracts). The significant negative correlations indicate that higher FA was associated with lower target errors, suggesting that less coherent microstructural organization explains poor bimanual tracking performance when the left hand needs to move faster than the right hand in older adults.

\section{Brain structure and neurophysiological function: correlation} between FA and IHI disinhibition

Only in older adults, positive correlations between FA and IHI disinhibition in DLPFC-M1 and PMd-M1 interactions were observed (Table 2; Figs. 10B, 11B), suggesting that higher FA values in the tracts between these brain regions were associated with greater disinhibitory IHI change during the preparatory period of the bimanual movements, particularly in nonisofrequency conditions (3:1 and 1:3) in older adults. These positive correlations also suggested that a lower FA value was significantly associated with inhibitory IHI changes. As such, the greater microstructural coherence in these WM tracts is beneficial for the disinhibition of interactions between brain regions, but not for the task-related suppression of interactions.

\section{Neurophysiological function and behavior: correlation between} IHI change and BTT target error

As illustrated in Table 3 and Figures $10 C$ and Figure $11 C$, in both young and older adults, increased IHI disinhibition from bilateral DLPFC and left PMd to opposite M1 was associated with lower errors in BTT performance (i.e., negative correlations were observed in nonisofrequency conditions). That is, the release of inhibition from these brain regions to the contralateral M1 during the preparatory movement period predicted the successful performance in the initial phase of the movement execution in 3:1 condition, in which the left hand needs to move 3 times faster than the right hand. In contrast, the reduced IHI disinhibition between the left PMd and right M1 was significantly associated with lower performance errors in the 1:3 condition (i.e., a positive correlation), suggesting that inhibitory influence from the left PMd to the right M1 was beneficial for the performance of 1:3 condition where the participants needed to slow down the left hand movement.

\section{Association between brain structure and behavior: partial correlation between FA and BTT target error controlling for the influence of IHI change in older adults}

It is possible to assume that the observed task-related changes in IHI rely on the coherent microstructural organization of the WM tracts. Accordingly, the significant bivariate correlations observed in older adults were then subjected to partial correlations to explore the relationship between brain structure and behavior while controlling for the effects of brain function (IHI). As there is only one ISI (i.e., LIHI) for the left DLPFCright M1 FA and BTT target error, a first-order partial correlation was computed controlling for the effect of LIHI modulation, whereas a second-order partial correlation was applied for the left PMd-right M1 interaction controlling the effect of SIHI and LIHI modulations. Interestingly, the correlation between the left DLPFC-right M1 FA and BTT target error partialling out the variance accounted for by the left DLPFC-right M1 IHI was not significant $(r=-0.22, p=$ 0.43 ), supporting the assumption that the relationship between FA value in left DLPFC-right M1 and BTT target error was largely mediated by the left DLPFC-right M1 IHI modulation. In contrast, the association between $\mathrm{FA}$ in the left PMd-right M1 and BTT target error remained statistically significant after partialling out the effect of left PMd-right M1 IHI modulation $(r=-0.67, p=0.01)$, suggesting that the relationships between FA in left PMd-right M1and BTT target error in the 3:1 condition were preserved beyond the mediating effects of IHI modulation in older adults.

\section{Discussion}

This is the first study to assess age-related changes in task-related modulation of interhemispheric projections from DLPFC and PMd to contralateral M1during the preparation of a complex bimanual coordination task. Most importantly, using a unique multimodal approach, we further investigated the interrelationships between brain WM microstructure (interhemispheric fiber tracts), neurophysiological function (task-related IHI modulations), and behavior in older adults. We report that the left PMd function, regulating corticomotor output emerging from the right $\mathrm{M} 1$, was largely maintained in healthy aging. In contrast, the ability to disinhibit projections from DLPFC to the contralateral M1 appeared to be declined in older adults and may be responsi- 

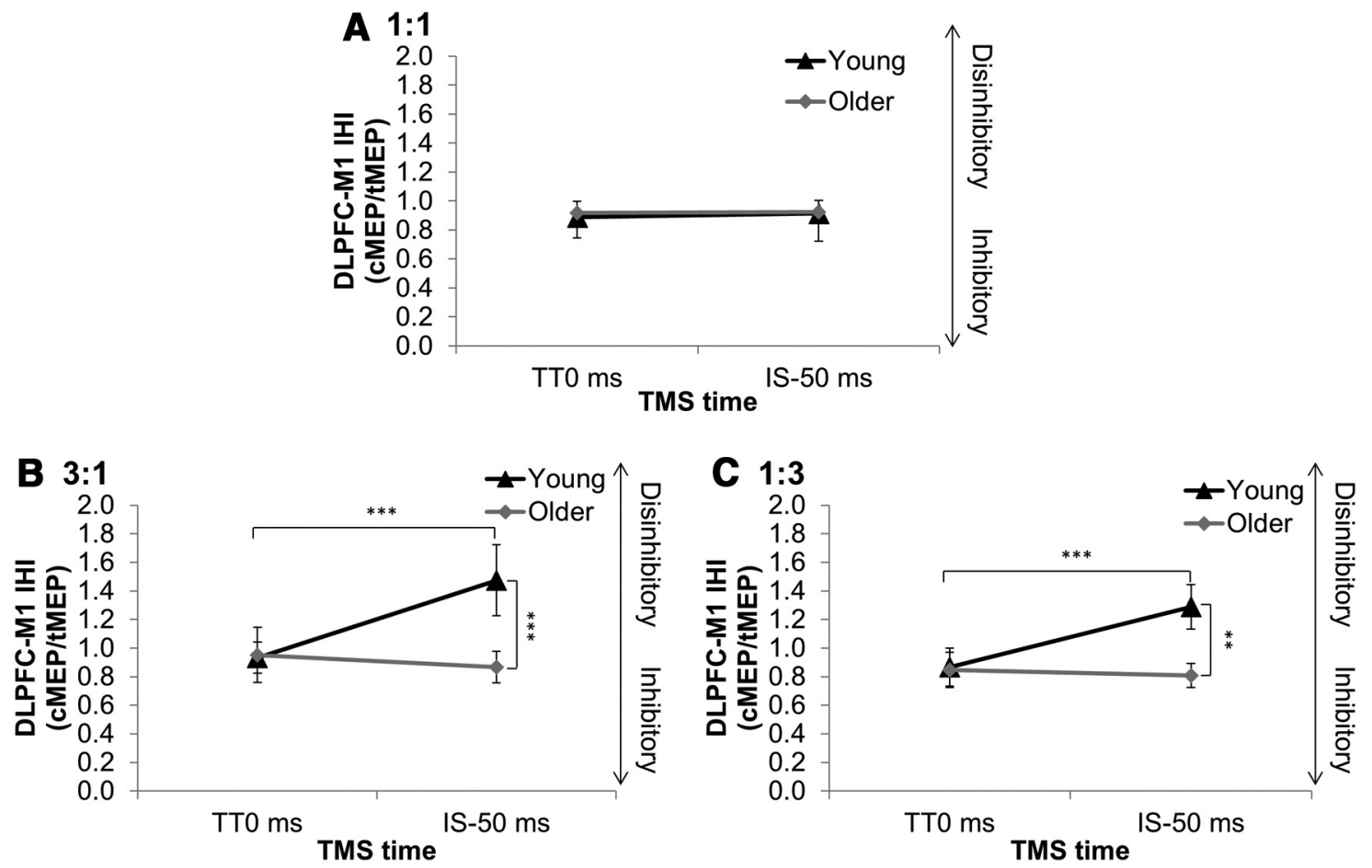

Figure 8. Mean DLPFC-M1 nIHI values for 1:1 (A), 3:1 (B), and 1:3 (C) frequency ratios at two TMS time points in young and older adults. Error bars indicate $95 \%\left(\mathrm{Cls} .{ }^{* *} p<0.01 .{ }^{* * *} p<0.001\right.$.

\section{A . L PMd - R M1}

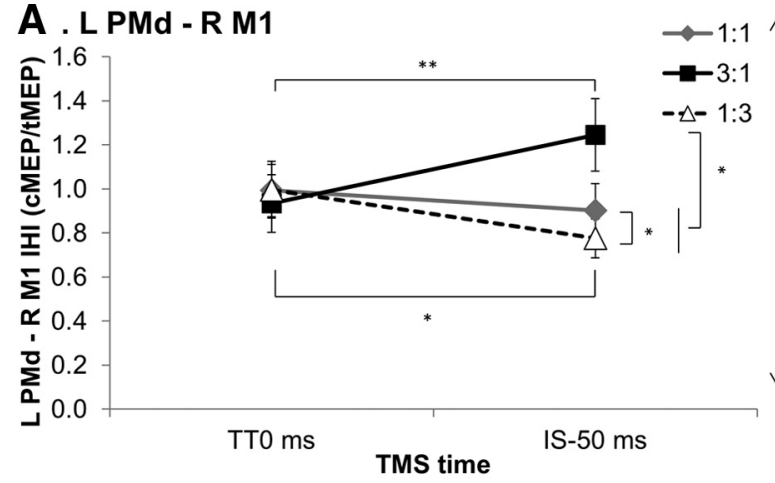

\section{B . R PMd - L M1}

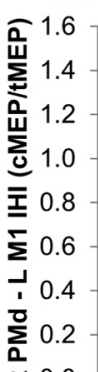

ณ 0.0
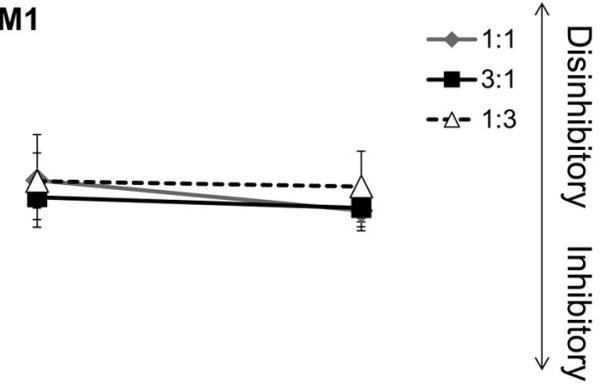

Figure 9. Mean IHI values for left PMd-right M1 $(\boldsymbol{A})$ and right PMd-left M1 (B) connection for different frequency ratios at two TMS time points. Values indicate mean IHI values across young and older adults as there were no interactions including group as a factor. Error bars indicate $95 \%$ Cls. ${ }^{*} p<0.05 .{ }^{* *} p<0.01$.

ble for their decreased bimanual performance. Notably, our novel finding is that associations between brain structure (i.e., FA of reconstructed tracts between ROIs), neurophysiological function (i.e., regulation of disinhibitory/inhibitory IHIs between

Table 1. Pearson's product-moment correlation coefficients for the association between $\mathrm{FA}$ values and target errors in $\mathrm{BTT}^{a}$

\begin{tabular}{|c|c|c|c|c|c|c|}
\hline & \multicolumn{3}{|c|}{ Young } & \multicolumn{3}{|c|}{ Older } \\
\hline & 1:1 & $3: 1$ & 1:3 & $1: 1$ & $3: 1$ & $1: 3$ \\
\hline \multicolumn{7}{|l|}{ DLPFC-M1 } \\
\hline Left to right & -0.08 & -0.13 & -0.29 & -0.02 & $-0.58^{a}$ & -0.44 \\
\hline Right to left & -0.20 & -0.05 & -0.30 & -0.05 & -0.29 & -0.44 \\
\hline \multicolumn{7}{|l|}{ PMd-M1 } \\
\hline Left to right & -0.24 & 0.05 & 0.35 & 0.28 & $-0.69^{a}$ & 0.43 \\
\hline Right to left & -0.21 & -0.37 & -0.19 & 0.12 & 0.18 & -0.27 \\
\hline \multicolumn{7}{|l|}{ M1-M1 } \\
\hline Left to right & -0.22 & 0.07 & 0.13 & -0.12 & $-0.59^{a}$ & 0.43 \\
\hline Right to left & -0.22 & -0.19 & 0.04 & -0.11 & -0.13 & -0.07 \\
\hline
\end{tabular}

${ }^{a}$ Significant correlation coefficients (critical $r= \pm 0.57, p=0.017$ ).

ROIs), and behavior (i.e., target error scores in BTT) are evident in older adults. This was not the case in young adults, in which only neurophysiological function was associated with behavior.

\section{Altered microstructural organization predicts changes in interhemispheric interaction and declined bimanual performance in older adults}

Mean FA values in all the reconstructed interhemispheric fiber tracts under consideration were lower in older adults relative to young adults, suggesting that the directional coherence of intracellular water diffusion declines with advancing age. These results are in agreement with a number of previous studies reporting reductions in FA with advancing age (Nusbaum et al., 2001; Sullivan et al., 2001; Abe et al., 2002; O'Sullivan et al., 2004; Serbruyns et al., 2015), with the largest decline evident in the frontal lobes (Grieve et al., 2007; Coxon et al., 2012).

The main focus of the present study was to explore the relationships between brain structure, neurophysiological function, and behavior. First, we investigated the correlation between the CSD-derived FA values of the interhemispheric fiber tracts, as a 


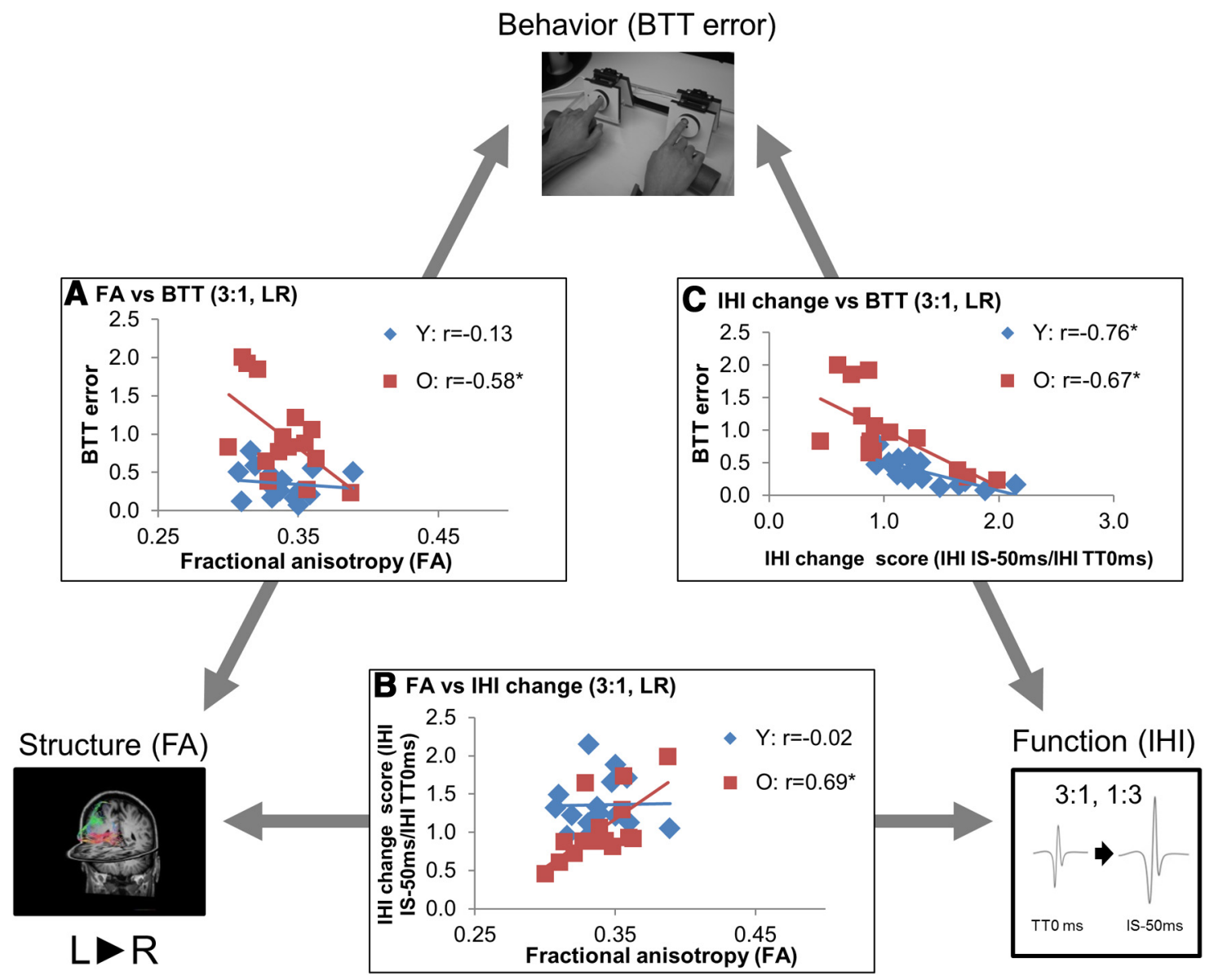

\section{DLPFC- M1 (R L, L $>R)$}

Figure 10. DLPFC-M1 interaction. Scatter plots representing relationships between brain structure, neurophysiological function, and behavior. Only in older adults, greater FA value was correlated with lower BTT target error $(\boldsymbol{A})$ and greater disinhibitory DLPFC-M1 modulation (value $>1)(\boldsymbol{B})$. For the relationship between neurophysiological function and behavior $(\boldsymbol{C})$, both in young and older adults, greater disinhibitory DLPFC-M1 modulation (value $>1$ ) during the preparatory period of BTT was associated with lower BTT target error.

measure of WM microstructure, and bimanual performance. Exclusively in older adults, higher FA values were selectively associated with BTT target errors only in the 3:1 condition in all of the left to right interhemispheric tracts (i.e., DLPFC-M1, PMd-M1, and M1-M1). These results are consistent with previous studies reporting associations between FA values in the callosal fibers (Fling and Seidler, 2012) or subregions of the CC (Serbruyns et al., 2015) and bimanual task performance.

Previous studies have shown that skilled bimanual performance heavily relies on intense interactions between the motor areas in both cerebral hemispheres (Gerloff and Andres, 2002), which are likely dependent on coherent WM microstructural organization (Gooijers and Swinnen, 2014). This view has been supported by investigation of the CC microstructure, including interhemispheric tracts connecting homotopic M1s in relation to bimanual movement performance (Fling and Seidler, 2012; Serbruyns et al., 2015). The current study extends this finding by demonstrating that the WM microstructural organization of interhemispheric fiber tracts between heterotopic cortical regions (i.e., nonprimary motor and primary motor regions) also plays an important role in bimanual coordination tasks, particularly when more complex movements are performed by older adults.
Similarly, WM microstructural organization also predicted neurophysiological function in older adults. Specifically, higher FA values in the heterotopic interhemispheric fiber tracts were positively correlated with disinhibitory IHI modulations in the corresponding pathway during task preparation, and this applied exclusively to older adults. Similarly, Fling and Seidler (2012) reported that more coherent microstructural organization of M1-M1 fiber tracts via CC predicted lower inhibitory interactions (i.e., greater disinhibition) between both M1s. It is important to note that the IHI measure (i.e., ipsilateral silent period) used in their study reflects the general state of inhibitory interactions between primary cortices rather than task-related modulations because it was not obtained during a bimanual movement task. In contrast, our IHI measures reflect task-related changes in transcallosal interactions between prefrontal/premotor regions and M1, as obtained during the preparatory movement period. Accordingly, it is conceivable that our results, together with those of Fling and Seidler (2012), point out that both static and dynamic interhemispheric interaction relies on the coherent WM microstructural organization in the aging brain.

A recent study revealed that higher FA was correlated with stronger interhemispheric inhibition between M1s at rest in healthy older adults (Wahl et al., 2015). In the present study, we 


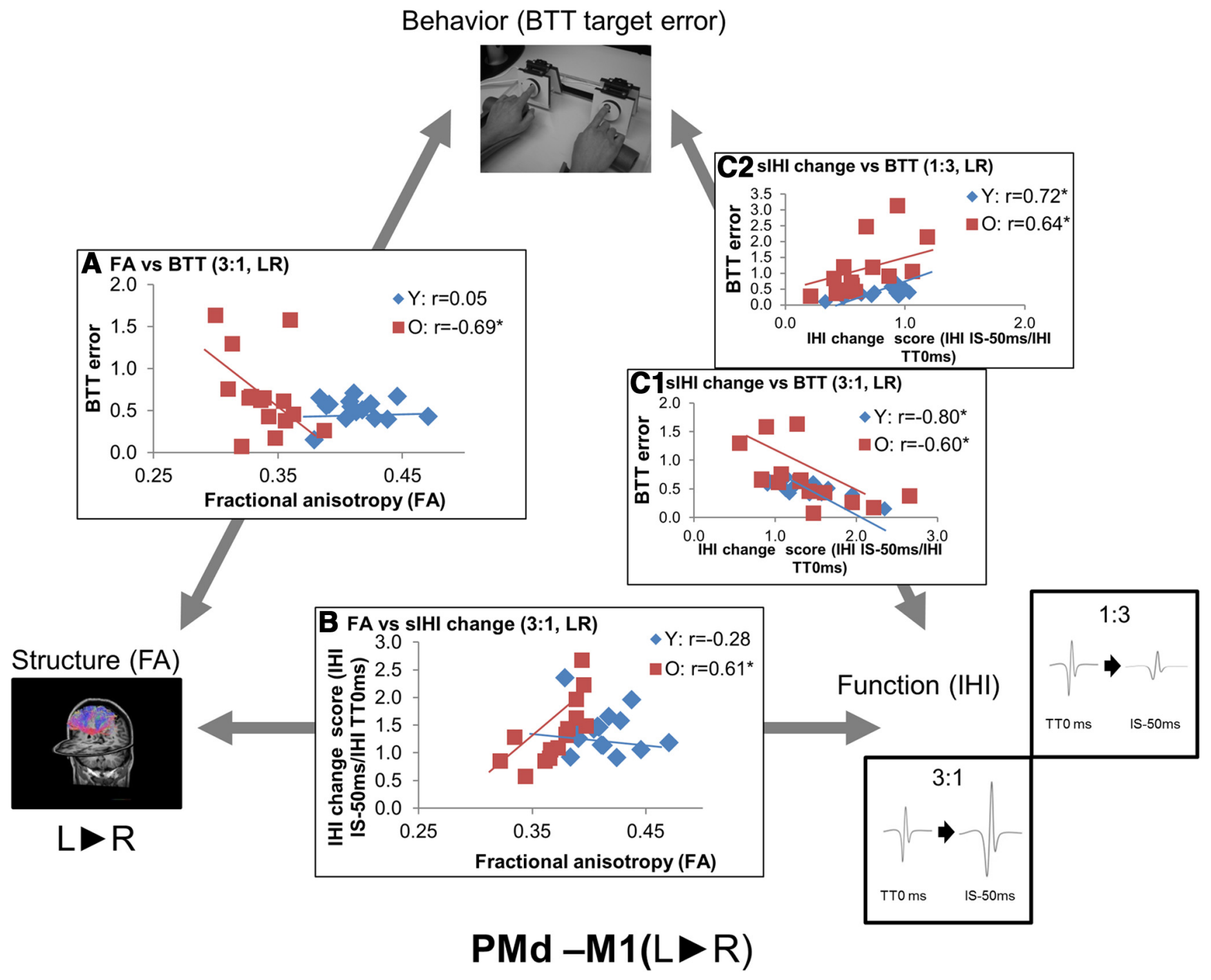

Figure 11. Left PMd-right M1 interaction. Scatter plots representing relationships between brain structure, neurophysiological function, and behavior. Only in older adults, greater FA value was correlated with lower BTT target error $(\boldsymbol{A})$ and greater disinhibitory DLPFC-M1 modulation $(\boldsymbol{B})$. For both young and older adults, task-specific modulations in left PMd-right M1 IHI were associated with lower target error. In 3:1 condition (C1), greater disinhibitory PMd-M1 modulation (value $>1$ ) was beneficial for BTT performance, whereas increased inhibitory modulation (value $<1$ ) was associated with lower BTT target error in the 1:3 condition (C2).

Table 2. Pearson's product-moment correlation coefficients for the association between $\mathrm{FA}$ values and IHI changes in each tract for young and older adults ${ }^{a}$

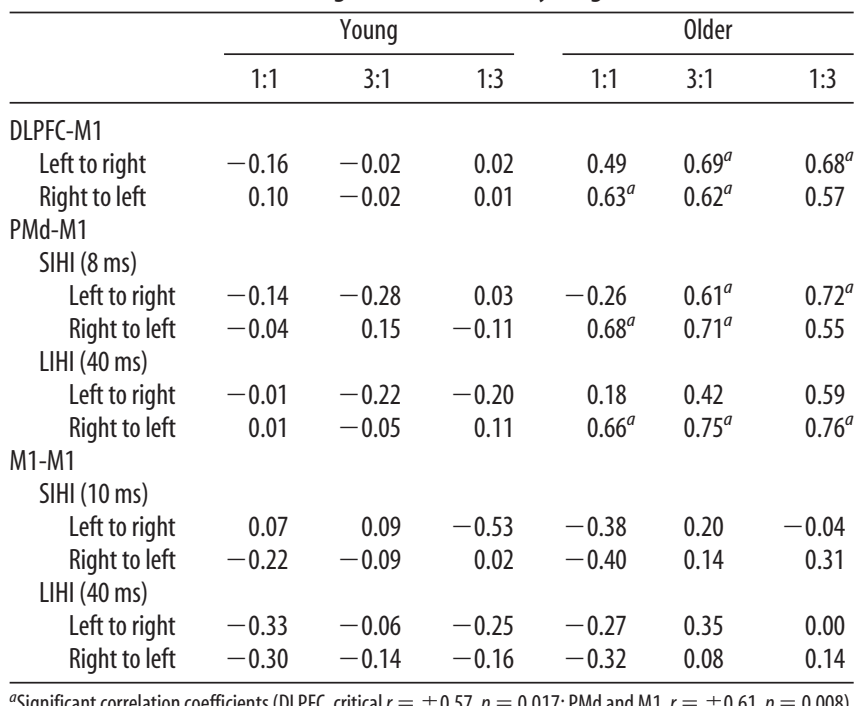

Table 3. Pearson's product-moment correlation coefficients for the association between IHI changes and target errors in $\mathrm{BTT}^{a}$

\begin{tabular}{|c|c|c|c|c|c|c|}
\hline & \multicolumn{3}{|c|}{ Young } & \multicolumn{3}{|c|}{ Older } \\
\hline & 1:1 & $3: 1$ & 1:3 & 1:1 & $3: 1$ & 1:3 \\
\hline \multicolumn{7}{|l|}{ DLPFC-M1 } \\
\hline Left to right & -0.16 & $-0.76^{a}$ & $-0.70^{a}$ & -0.34 & $-0.67^{a}$ & $-0.57^{\circ}$ \\
\hline Right to left & -0.29 & $-0.72^{a}$ & $-0.71^{a}$ & -0.08 & $-0.73^{a}$ & $-0.57^{\circ}$ \\
\hline \multicolumn{7}{|l|}{ PMd-M1 } \\
\hline \multicolumn{7}{|l|}{ SIHI (8 ms) } \\
\hline Left to right & 0.15 & $-0.80^{a}$ & $0.72^{a}$ & -0.32 & $-0.60^{a}$ & $0.64^{a}$ \\
\hline Right to left & -0.35 & -0.01 & -0.03 & -0.31 & 0.04 & -0.23 \\
\hline \multicolumn{7}{|l|}{ LIHI (40 ms) } \\
\hline Left to right & 0.05 & $-0.79^{a}$ & $0.61^{a}$ & 0.01 & $-0.60^{a}$ & $0.67^{\circ}$ \\
\hline Right to left & -0.04 & -0.01 & -0.12 & 0.08 & -0.11 & -0.23 \\
\hline \multicolumn{7}{|l|}{ M1-M1 } \\
\hline \multicolumn{7}{|l|}{ SIHI (10 ms) } \\
\hline Left to right & -0.04 & -0.04 & -0.40 & -0.11 & -0.21 & -0.25 \\
\hline Right to left & 0.21 & 0.24 & -0.17 & 0.29 & -0.48 & -0.23 \\
\hline \multicolumn{7}{|l|}{ LIHI (40 ms) } \\
\hline Left to right & -0.02 & 0.00 & -0.21 & -0.22 & 0.25 & 0.21 \\
\hline Right to left & -0.12 & 0.12 & 0.23 & 0.04 & -0.29 & -0.16 \\
\hline
\end{tabular}

${ }^{a}$ Significant correlation coefficients (critical $r= \pm 0.57$ ) 
examined the relationship between task-related IHI modulation and FA between M1-M1 interhemispheric pathways, which did not show significant correlations. Apparently, the role of M1-M1 IHI may have been less prominent during the preparatory period compared with actual movement execution.

\section{Maintained left PMd function in healthy aging}

The involvement of the PMd in complex bimanual movements has been demonstrated in young adults (van den Berg et al., 2010; Liuzzi et al., 2011). Our study is the first to investigate the role of the PMd in the regulation of bimanual movements in older adults. For both age groups, task-specific modulations in the interaction between the left PMd and right M1 during the preparation of bimanual movement were observed, which likely reflects the gating role of the PMd for regulating motor output. Specifically, in the 3:1 condition, in which the left hand was required to move faster than the right hand, the left PMd disinhibited the right $\mathrm{M} 1$, possibly increasing the corticomotor output emerging from the right M1, whereas the interaction was inhibitory when the left hand needed to move slower than the right hand in the $1: 3$ condition. This reveals, for the first time, a unique taskdependent gating function of the left PMd during bimanual movements requiring differential motor output for each limb.

A growing body of literature suggests that the PMd undergoes functional and structural changes in the aging brain (SolesioJofre et al., 2014; e.g., Levin et al., 2014). Furthermore, there is evidence to suggest that ipsilateral PMd-M1 connectivity (in comparison, our study examined contralateral PMd-M1 interaction) is reduced in older adults at rest (Ni et al., 2015). However, because older adults showed comparable IHI modulation between left PMd and right M1 as young adults in our study, we conclude that the functional task-specific gating of motor output in the left PMd remained relatively intact. Our current results are in agreement with a previous study also reporting maintained left PMd function in older adults during the preparatory phase of a simple reaction time task (Fujiyama et al., 2013).

\section{Changes in DLPFC-M1 interaction are associated with declined bimanual movement in older adults}

In contrast to PMd-M1 IHI, older adults failed to show any taskrelated modulations in the DLPFC-M1 IHI, whereas young adults showed disinhibitory IHI modulations in the nonisofrequency conditions (3:1 and 1:3). Furthermore, this selective disinhibition during the preparation of more complex movements seems instrumental for behavior as correlational analyses revealed significant relationships between IHI modulations and BTT performance both in young and older adults. Therefore, the lack of modulation in DLPFC-M1 IHI (at the group level) may perhaps be responsible for the declined BTT performance in older adults. The involvement of the DLPFC in the preparation of these complex bimanual movements likely reflects cognitive control of movement and reliance on internal representations (Miller and Cohen, 2001; Duque et al., 2012). To determine the causal relationship between DLPFC function and performance of bimanual movements, the use of a repetitive TMS protocol to disrupt the function of the DLPFC during bimanual movements would be helpful. A limitation of the present study is that the stimulation sites were selected on the basis of anatomical landmarks while making use of task-related fMRI in the same subjects to determine the maximum activation site might further improve brain area location accuracy.

Using similar interlimb coordination tasks, previous fMRI studies demonstrated that older adults showed higher activation of the DLPFC relative to young adults (Heuninckx et al., 2005, 2008; Goble et al., 2010), suggesting that older adults recruit DLPFC to implement a higher degree of cognitive control of movement that was not needed in young adults. In line with these findings, the correlational analyses in the current study also revealed the importance of the DLPFC in the regulation of upcoming movements for older adults, yet we observed that brain structure and neurophysiological function connecting the DLPFC and contralateral M1 deteriorated with advancing age.

Interestingly, in older adults, we observed a number of significant positive correlations between FA values and IHI changes in the projection from DLPFC and PMd to the contralateral M1 (Table 2), suggesting that more organized WM microstructure likely provides a foundation for disinhibitory interactions (but not inhibitory) between these cortical regions. Indeed, agerelated volume reduction of the DLPFC is associated with loss of glutamatergic synapses (Morrison and Baxter, 2012). Furthermore, callosal axons that enable interhemispheric interactions mainly depend on the glutamate neurotransmitter and are thus thought to be excitatory (disinhibitory) rather than inhibitory (van der Knaap and van der Ham, 2011). Notably, this view is consistent with the observed correlation between FA and BTT performance in the 3:1 conditions (Table 1). In older adults, lower FA in all reconstructed interhemispheric fiber tracts from left to right hemisphere (i.e., DLPFC-M1, PMd-M1, and M1M1) predicted higher BTT target errors selectively in the 3:1 task condition, during which the cortical output to the left hand needs to be increased. Therefore, we speculate that these structural changes in the aging brain, particularly in the DLPFC and its projection via CC to the contralateral M1, may have resulted in a reduced ability to modulate disinhibitory DLPFC-M1 IHI in a task-specific manner, and this effect was associated with declined bimanual performance.

In conclusion, the current study provided the first known evidence of dynamic functional declines in interhemispheric projections from DLPFC to the contralateral M1 in older adults. Moreover, the functional interhemispheric projections in the aging brain appeared to rely on the coherence of the microstructure of the interhemispheric fibers. More specifically, age-related changes in white matter microstructure were associated with dysfunctional regulation of releasing interhemispheric inhibition during movement preparation, particularly in DLPFC-M1, which most likely accounted for declined bimanual performance. As such, the present results provide a strong case for interactions between brain structure, function, and behavior in the aging brain.

\section{References}

Abe O, Aoki S, Hayashi N, Yamada H, Kunimatsu A, Mori H, Yoshikawa T, Okubo T, Ohtomo K (2002) Normal aging in the central nervous system: quantitative MR diffusion-tensor analysis. Neurobiol Aging 23: 433-441. CrossRef Medline

Barrick TR, Charlton RA, Clark CA, Markus HS (2010) White matter structural decline in normal ageing: a prospective longitudinal study using tract-based spatial statistics. Neuroimage 51:565-577. CrossRef Medline

Basser PJ, Pierpaoli C (1996) Microstructural and physiological features of tissues elucidated by quantitative-diffusion-tensor MRI. J Magn Reson B 111:209-219. CrossRef Medline

Bäumer T, Bock F, Koch G, Lange R, Rothwell JC, Siebner HR, Münchau A (2006) Magnetic stimulation of human premotor or motor cortex produces interhemispheric facilitation through distinct pathways. J Physiol 572:857-868. CrossRef Medline

Beets IA, Gooijers J, Boisgontier MP, Pauwels L, Coxon JP, Wittenberg G, Swinnen SP (2015) Reduced neural differentiation between feedback 
conditions after bimanual coordination training with and without augmented visual feedback. Cereb Cortex 25:1958-1969. CrossRef Medline

Carson RG, Riek S, Mackey DC, Meichenbaum DP, Willms K, Forner M, Byblow WD (2004) Excitability changes in human forearm corticospinal projections and spinal reflex pathways during rhythmic voluntary movement of the opposite limb. J Physiol 560:929-940. CrossRef Medline

Chamberland M, Whittingstall K, Fortin D, Mathieu D, Descoteaux M (2014) Real-time multi-peak tractography for instantaneous connectivity display. Front Neuroinform 8:59. CrossRef Medline

Chowdhury SA, Kawashima T, Konishi T, Matsunami K (1996) GABAergic characteristics of transcallosal activity of cat motor cortical neurons. Neurosci Res 26:323-333. CrossRef Medline

Coxon JP, Van Impe A, Wenderoth N, Swinnen SP (2012) Aging and inhibitory control of action: cortico-subthalamic connection strength predicts stopping performance. J Neurosci 32:8401-8412. CrossRef Medline

Debaere F, Wenderoth N, Sunaert S, Van Hecke P, Swinnen SP (2004) Changes in brain activation during the acquisition of a new bimanual coodination task. Neuropsychologia 42:855-867. CrossRef Medline

Duque J, Labruna L, Verset S, Olivier E, Ivry RB (2012) Dissociating the role of prefrontal and premotor cortices in controlling inhibitory mechanisms during motor preparation. J Neurosci 32:806-816. CrossRef Medline

Fan Q, Nummenmaa A, Witzel T, Zanzonico R, Keil B, Cauley S, Polimeni JR, Tisdall D, Van Dijk KR, Buckner RL, Wedeen VJ, Rosen BR, Wald LL (2014) Investigating the capability to resolve complex white matter structures with high $b$-value diffusion magnetic resonance imaging on the MGH-USC Connectom scanner. Brain Connect 4:718-726. CrossRef Medline

Ferbert A, Priori A, Rothwell JC, Day BL, Colebatch JG, Marsden CD (1992) Interhemispheric inhibition of the human motor cortex. J Physiol 453: 525-546. CrossRef Medline

Fink GR, Frackowiak RS, Pietrzyk U, Passingham RE (1997) Multiple nonprimary motor areas in the human cortex. J Neurophysiol 77: 2164-2174. Medline

Fling BW, Seidler RD (2012) Fundamental differences in callosal structure, neurophysiologic function, and bimanual control in young and older adults. Cereb Cortex 22:2643-2652. CrossRef Medline

Fujiyama H, Garry MI, Martin FH, Summers JJ (2010) An ERP study of age-related differences in the central cost of interlimb coordination. Psychophysiology 47:501-511. CrossRef Medline

Fujiyama H, Hinder MR, Schmidt MW, Garry MI, Summers JJ (2012) Agerelated differences in corticospinal excitability and inhibition during coordination of upper and lower limbs. Neurobiol Aging 33:1484. CrossRef Medline

Fujiyama H, Hinder MR, Summers JJ (2013) Functional role of left PMd and left M1 during preparation and execution of left hand movements in older adults. J Neurophysiol 110:1062-1069. CrossRef Medline

Gazzaniga MS (2005) Forty-five years of split-brain research and still going strong. Nat Rev Neurosci 6:653-659. CrossRef Medline

Geffen GM, Jones DL, Geffen LB (1994) Interhemispheric control of manual motor activity. Behav Brain Res 64:131-140. CrossRef Medline

Gerloff C, Andres FG (2002) Bimanual coordination and interhemispheric interaction. Acta Psychol (Amst) 110:161-186. CrossRef Medline

Gerloff C, Cohen LG, Floeter MK, Chen R, Corwell B, Hallett M (1998) Inhibitory influence of the ipsilateral motor cortex on responses to stimulation of the human cortex and pyramidal tract. J Physiol 510:249-259. CrossRef Medline

Goble DJ, Coxon JP, Van Impe A, De Vos J, Wenderoth N, Swinnen SP (2010) The neural control of bimanual movements in the elderly: brain regions exhibiting age-related increases in activity, frequency-induced neural modulation, and task-specific compensatory recruitment. Hum Brain Mapp 31:1281-1295. CrossRef Medline

Gooijers J, Swinnen SP (2014) Interactions between brain structure and behavior: the corpus callosum and bimanual coordination. Neurosci Biobehav Rev 43:1-19. CrossRef Medline

Gooijers J, Caeyenberghs K, Sisti HM, Geurts M, Heitger MH, Leemans A, Swinnen SP (2013) Diffusion tensor imaging metrics of the corpus callosum in relation to bimanual coordination: effect of task complexity and sensory feedback. Hum Brain Mapp 34:241-252. CrossRef Medline

Gooijers J, Leemans A, Van Cauter S, Sunaert S, Swinnen SP, Caeyenberghs K (2014) White matter organization in relation to upper limb motor con- trol in healthy subjects: exploring the added value of diffusion kurtosis imaging. Brain Struct Funct 219:1627-1638. CrossRef Medline

Grieve SM, Williams LM, Paul RH, Clark CR, Gordon E (2007) Cognitive aging, executive function, and fractional anisotropy: a diffusion tensor MR imaging study. AJNR Am J Neuroradiol 28:226-235. Medline

Hallett M (2000) Disorder of movement preparation in dystonia. Brain 123: 1765-1766. CrossRef Medline

Heitger MH, Goble DJ, Dhollander T, Dupont P, Caeyenberghs K, Leemans A, Sunaert S, Swinnen SP (2013) Bimanual motor coordination in older adults is associated with increased functional brain connectivity: a graphtheoretical analysis. PLoS One 8:e62133. CrossRef Medline

Heuninckx S, Wenderoth N, Debaere F, Peeters R, Swinnen SP (2005) Neural basis of aging: the penetration of cognition into action control. J Neurosci 25:6787-6796. CrossRef Medline

Heuninckx S, Wenderoth N, Swinnen SP (2008) Systems neuroplasticity in the aging brain: recruiting additional neural resources for successful motor performance in elderly persons. J Neurosci 28:91-99. CrossRef Medline

Hinder MR (2012) Interhemispheric connectivity between distinct motor regions as a window into bimanual coordination. J Neurophysiol 107: 1791-1794. CrossRef Medline

Hinder MR, Fujiyama H, Summers JJ (2012) Premotor-motor interhemispheric inhibition is released during movement initiation in older but not young adults. PLoS One 7:e52573. CrossRef Medline

Irlbacher K, Brocke J, Mechow JV, Brandt SA (2007) Effects of GABA(A) and $\operatorname{GABA}(\mathrm{B})$ agonists on interhemispheric inhibition in man. Clin Neurophysiol 118:308-316. CrossRef Medline

Kim JE, Oh JS, Sung JJ, Lee KW, Song IC, Hong YH (2014) Diffusion tensor tractography analysis of the corpus callosum fibers in amyotrophic lateral sclerosis. J Clin Neurol 10:249-256. CrossRef Medline

Koch G, Franca M, Del Olmo MF, Cheeran B, Milton R, Alvarez Sauco M, Rothwell JC (2006) Time course of functional connectivity between dorsal premotor and contralateral motor cortex during movement selection. J Neurosci 26:7452-7459. CrossRef Medline

Kroeger J, Bäumer T, Jonas M, Rothwell JC, Siebner HR, Münchau A (2010) Charting the excitability of premotor to motor connections while withholding or initiating a selected movement. Eur J Neurosci 32:1771-1779. CrossRef Medline

Leemans A, Jeurissen B, Sijbers J, Jones DK (2009) ExploreDTI: a graphical toolbox for processing, analyzing, and visualizing diffusion MR data. In: 17th Annual Meeting of International Society of Magnetic Resonance Medicine, p 3537. Honolulu.

Levin O, Fujiyama H, Boisgontier MP, Swinnen SP, Summers JJ (2014) Aging and motor inhibition: a converging perspective provided by brain stimulation and imaging approaches. Neurosci Biobehav Rev 43: 100-117. CrossRef Medline

Liuzzi G, Hörniss V, Zimerman M, Gerloff C, Hummel FC (2011) Coordination of uncoupled bimanual movements by strictly timed interhemispheric connectivity. J Neurosci 31:9111-9117. CrossRef Medline

Mattay VS, Fera F, Tessitore A, Hariri AR, Das S, Callicott JH, Weinberger DR (2002) Neurophysiological correlates of age-related changes in human motor function. Neurology 58:630-635. CrossRef Medline

Mayka MA, Corcos DM, Leurgans SE, Vaillancourt DE (2006) Threedimensional locations and boundaries of motor and premotor cortices as defined by functional brain imaging: a meta-analysis. Neuroimage 31: 1453-1474. CrossRef Medline

Miller EK, Cohen JD (2001) An integrative theory of prefrontal cortex function. Annu Rev Neurosci 24:167-202. CrossRef Medline

Mochizuki H, Huang YZ, Rothwell JC (2004) Interhemispheric interaction between human dorsal premotor and contralateral primary motor cortex. J Physiol 561:331-338. CrossRef Medline

Mori S, Oishi K, Jiang H, Jiang L, Li X, Akhter K, Hua K, Faria AV, Mahmood A, Woods R, Toga AW, Pike GB, Neto PR, Evans A, Zhang J, Huang H, Miller MI, van Zijl P, Mazziotta J (2008) Stereotaxic white matter atlas based on diffusion tensor imaging in an ICBM template. Neuroimage 40:570-582. CrossRef Medline

Morrison JH, Baxter MG (2012) The ageing cortical synapse: hallmarks and implications for cognitive decline. Nat Rev Neurosci 13:240-250. CrossRef Medline

Mylius V, Ayache SS, Ahdab R, Farhat WH, Zouari HG, Belke M, Brugières P, Wehrmann E, Krakow K, Timmesfeld N, Schmidt S, Oertel WH, Knake S, Lefaucheur JP (2013) Definition of DLPFC and M1 according to ana- 
tomical landmarks for navigated brain stimulation: inter-rater reliability, accuracy, and influence of gender and age. Neuroimage 78:224-232. CrossRef Medline

Nasreddine ZS, Phillips NA, Bédirian V, Charbonneau S, Whitehead V, Collin I, Cummings JL, Chertkow H (2005) The Montreal Cognitive Assessment, MoCA: a brief screening tool for mild cognitive impairment. J Am Geriatr Soc 53:695-699. CrossRef Medline

Ni Z, Gunraj C, Nelson AJ, Yeh IJ, Castillo G, Hoque T, Chen R (2009) Two phases of interhemispheric inhibition between motor related cortical areas and the primary motor cortex in human. Cereb Cortex 19:1654-1665. CrossRef Medline

Ni Z, Isayama R, Castillo G, Gunraj C, Saha U, Chen R (2015) Reduced dorsal premotor cortex and primary motor cortex connectivity in older adults. Neurobiol Aging 36:301-303. CrossRef Medline

Nusbaum AO, Tang CY, Buchsbaum MS, Wei TC, Atlas SW (2001) Regional and global changes in cerebral diffusion with normal aging. AJNR Am J Neuroradiol 22:136-142. Medline

Oldfield RC (1971) The assessment and analysis of handedness: the Edinburgh Inventory. Neuropsychologia 9:97-113. CrossRef Medline

O'Shea J, Sebastian C, Boorman ED, Johansen-Berg H, Rushworth MF (2007) Functional specificity of human premotor-motor cortical interactions during action selection. Eur J Neurosci 26:2085-2095. CrossRef Medline

O'Sullivan M, Morris RG, Huckstep B, Jones DK, Williams SC, Markus HS (2004) Diffusion tensor MRI correlates with executive dysfunction in patients with ischaemic leukoaraiosis. J Neurol Neurosurg Psychiatry 75: 441-447. CrossRef Medline

Picard N, Strick PL (2001) Imaging the premotor areas. Curr Opin Neurobiol 11:663-672. CrossRef Medline

Pierpaoli C, Basser PJ (1996) Toward a quantitative assessment of diffusion anisotropy. Magn Reson Med 36:893-906. CrossRef Medline

Poot DH, den Dekker AJ, Achten E, Verhoye M, Sijbers J (2010) Optimal experimental design for diffusion kurtosis imaging. IEEE Trans Med Imaging 29:819-829. CrossRef Medline

Reuter-Lorenz PA, Cappell KA (2008) Neurocognitive aging and the compensation hypothesis. Curr Directions Psychol Sci 17:177-182. CrossRef

Rossi S, Hallett M, Rossini PM, Pascual-Leone A (2009) Safety, ethical considerations, and application guidelines for the use of transcranial magnetic stimulation in clinical practice and research. Clin Neurophysiol 120:2008-2039. CrossRef Medline

Sanger TD, Garg RR, Chen R (2001) Interactions between two different inhibitory systems in the human motor cortex. J Physiol 530:307-317. CrossRef Medline

Serbruyns L, Gooijers J, Caeyenberghs K, Meesen RL, Cuypers K, Sisti HM, Leemans A, Swinnen SP (2015) Bimanual motor deficits in older adults predicted by diffusion tensor imaging metrics of corpus callosum subregions. Brain Struct Funct 220:273-290. CrossRef Medline

Sink CA, Stroh HR (2006) Practical significance: the use of effect sizes in school counseling research. Professional School Counseling 9:401-411. CrossRef

Sisti HM, Geurts M, Clerckx R, Gooijers J, Coxon JP, Heitger MH, Caeyenberghs K, Beets IA, Serbruyns L, Swinnen SP (2011) Testing multiple coordination constraints with a novel bimanual visuomotor task. PLoS One 6:e23619. CrossRef Medline

Sisti HM, Geurts M, Gooijers J, Heitger MH, Caeyenberghs K, Beets IA, Serbruyns L, Leemans A, Swinnen SP (2012) Microstructural organization of corpus callosum projections to prefrontal cortex predicts bimanual motor learning. Learn Mem 19:351-357. CrossRef Medline

Smith SM, Jenkinson M, Woolrich MW, Beckmann CF, Behrens TE, Johansen-Berg H, Bannister PR, De Luca M, Drobnjak I, Flitney DE,
Niazy RK, Saunders J, Vickers J, Zhang Y, De Stefano N, Brady JM, Matthews PM (2004) Advances in functional and structural MR image analysis and implementation as FSL. Neuroimage 23[Suppl 1]:208-219.

Smith SM, Jenkinson M, Johansen-Berg H, Rueckert D, Nichols TE, Mackay CE, Watkins KE, Ciccarelli O, Cader MZ, Matthews PM, Behrens TE (2006) Tract-based spatial statistics: voxelwise analysis of multi-subject diffusion data. Neuroimage 31:1487-1505. CrossRef Medline

Solesio-Jofre E, Serbruyns L, Woolley DG, Mantini D, Beets IA, Swinnen SP (2014) Aging effects on the resting state motor network and interlimb coordination. Hum Brain Mapp 35:3945-3961. CrossRef Medline

Sterr A, Dean P (2008) Neural correlates of movement preparation in healthy ageing. Eur J Neurosci 27:254-260. CrossRef Medline

Sullivan EV, Adalsteinsson E, Hedehus M, Ju C, Moseley M, Lim KO, Pfefferbaum A (2001) Equivalent disruption of regional white matter microstructure in ageing healthy men and women. Neuroreport 12:99-104. CrossRef Medline

Summers JJ, Lewis J, Fujiyama H (2010) Aging effects on event and emergent timing in bimanual coordination. Hum Mov Sci 29:820-830. CrossRef Medline

Swinnen SP, Gooijers J (2015) Bimanual coordination. In: Brain mapping: an encyclopedic reference (Toga AW, ed). Oxford: Elsevier.

Swinnen SP, Wenderoth N (2004) Two hands, one brain: cognitive neuroscience of bimanual skill. Trends Cogn Sci 8:18-25. CrossRef Medline

Swinnen SP, Verschueren S, Bogaerts H, Dounskaia N, Lee T, Stelmach G, Serrien D (1998) Age-related deficits in motor learning and differences in feedback processing during the production of a bimanual coordination pattern. Cogn Neuropsychol 15:439-466. CrossRef

Talelli P, Waddingham W, Ewas A, Rothwell JC, Ward NS (2008) The effect of age on task-related modulation of interhemispheric balance. Exp Brain Res 186:59-66. CrossRef Medline

Tournier JD, Calamante F, Gadian DG, Connelly A (2004) Direct estimation of the fiber orientation density function from diffusion-weighted MRI data using spherical deconvolution. Neuroimage 23:1176-1185. CrossRef Medline

Tournier JD, Calamante F, Connelly A (2007) Robust determination of the fibre orientation distribution in diffusion MRI: non-negativity constrained superresolved spherical deconvolution. Neuroimage 35:1459-1472. CrossRef Medline

Tournier JD, Yeh CH, Calamante F, Cho KH, Connelly A, Lin CP (2008) Resolving crossing fibres using constrained spherical deconvolution: validation using diffusion-weighted imaging phantom data. Neuroimage 42:617-625. CrossRef Medline

Tournier JD, Mori S, Leemans A (2011) Diffusion tensor imaging and beyond. Magn Reson Med 65:1532-1556. CrossRef Medline

Uehara K, Morishita T, Kubota S, Funase K (2013) Neural mechanisms underlying the changes in ipsilateral primary motor cortex excitability during unilateral rhythmic muscle contraction. Behav Brain Res 240:33-45. CrossRef Medline

van den Berg FE, Swinnen SP, Wenderoth N (2010) Hemispheric asymmetries of the premotor cortex are task specific as revealed by disruptive TMS during bimanual versus unimanual movements. Cereb Cortex 20:2842-2851. CrossRef Medline

van der Knaap LJ, van der Ham IJ (2011) How does the corpus callosum mediate interhemispheric transfer? A review. Behav Brain Res 223: 211-221. CrossRef Medline

Wahl M, Lauterbach-Soon B, Hattingen E, Hubers A, Ziemann U (2015) Callosal anatomical and effective connectivity between primary motor cortices predicts visually cued bimanual temporal coordination performance. Brain Struct Funct.

Ward NS (2006) Compensatory mechanisms in the aging motor system. Ageing Res Rev 5:239-254. CrossRef Medline 